Article

\title{
Modelling Approach for Predicting the Impact of Changing Temperature Conditions on Grapevine Canopy Architectures
}

\author{
Dominik Schmidt $^{1, *(\mathbb{D})}$, Christopher Bahr ${ }^{2}$, Matthias Friedel ${ }^{2} \mathbb{D}$ and Katrin Kahlen ${ }^{3}$ \\ 1 Department of Modeling and Systems Analysis, Hochschule Geisenheim University, Von-Lade-Str. 1, \\ 65366 Geisenheim, Germany \\ 2 Department of General and Organic Viticulture, Hochschule Geisenheim University, Von-Lade-Str. 1, \\ 65366 Geisenheim, Germany \\ 3 Department of Vegetable Crops, Hochschule Geisenheim University, Von-Lade-Str. 1, \\ 65366 Geisenheim, Germany \\ * Correspondence: dominik.schmidt@hs-gm.de; Tel.: +49-6722-502-79734
}

Received: 29 June 2019; Accepted: 31 July 2019; Published: 3 August 2019

\begin{abstract}
Future climatic conditions might have severe effects on grapevine architecture, which will be highly relevant for vineyard management decisions on shoot positioning, pruning or cutting. This study was designed to help gaining insight into how, in particular, increasing temperatures might affect grapevine canopies. We developed a functional-structural model for Riesling, Virtual Riesling, based on digitised data of real plants and a comprehensive state-of-the-art data analysis. The model accounts for the variability in temperature-sensitive morphological processes, such as bud break and appearance rates. Our simulation study using historical weather data revealed significant effects of the thermal time course over the year on bud burst of the cane and on primary shoots. High variabilities in these events affect canopy growth and leaf area distribution. This report shows that Virtual Riesling can be useful in assessing the significance of changing temperatures for grapevine architecture and thereby considering management techniques such as vertical shoot positioning. Further developments of Virtual Riesling might support the knowledge gain for developing necessary adaptations in future vineyard management and, thus, facilitate future work on climate change research using functional-structural model approaches.
\end{abstract}

Keywords: grapevine; Virtual Riesling; climate change; temperature; plant architecture; crop management; modelling

\section{Introduction}

Climate change will affect traditional forms of viticulture from multiple perspectives. Temperature increases in wine growing regions with a cool to moderate climate have already advanced the onset of ripening by two weeks in the past 20 years and are expected to advance phenological development by another two weeks in the near future [1]. An earlier ripening period will expose ripening grapes to higher temperatures and lead to a higher degree of alcohol, a lower concentration of organic acids and to changes in the aroma composition of wines. This may ultimately lead to a loss of typicality of regional wine styles. Elevated temperatures during shoot growth and ripening will also lead to an increased pressure of infection of Plasmopara viticola [2] and Botrytis cinerea in most European regions [3]. An earlier bud break will also increase the risk of late frost damages in grapevines. Apart from accelerating the phenological development of grapevines, increasing temperatures will also affect grapevine growth and shoot architecture [4]. Developmental rates of leaf primordia, unfolded and fully expanded leaves are constant when expressed in thermal time as observed for 
naturally varying field and greenhouse conditions [5,6]. For example, appearance rates linearly relate to temperature. However, even this stable program might be affected by the trophic state and the water status of the vine [7]. In addition, growth rates and durations of Grenache Noir are not stable when expressed in thermal time [5] and different grapevine cultivars might respond differently to changes in temperatures, as shown by Luchaire et al. [6]. In the growth chamber experiment of Buttrose [8], which covered a wide range of constant temperatures from $15^{\circ} \mathrm{C}$ to $30^{\circ} \mathrm{C}$, Riesling reached maximal shoot lengths at $30^{\circ} \mathrm{C}$, whereas the maximal node number was reached at lower temperatures $\left(25^{\circ} \mathrm{C}\right)$. At even lower temperatures $\left(<20^{\circ} \mathrm{C}\right)$, relatively more dry weight was distributed to the leaves than at higher temperatures, and the lengths of lateral shoots sharply increased at extreme temperatures $\left(>30^{\circ} \mathrm{C}\right)$. However, it is not known how this knowledge transfers to fully grown vines in the field. The temperature responsiveness of developmental growth processes may also be summarised by common Arrhenius-like functions [9]. The increasing phase between base temperature and below optimal temperatures is in agreement with the thermal-based program, whereas responses to extreme, higher temperature conditions are non-linear with different pattern. Overall, these complex patterns with both thermal-stable and different organ-specific temperature responses will challenge the predictability of grapevine architecture under future environmental conditions and the wine industry will have to cope with these challenges [10]. In the long run, it may be necessary to either move production of traditional cultivars to cooler vineyards, e.g., at higher elevation, or adapt the cultivar profile of existing wine regions. In the medium term, however, the production of typical wines from traditional cultivars could be maintained if vineyard management techniques are adapted [11]. Developing necessary adaptations in vineyard management will require enormous scientific, experimental and practical efforts. Modelling approaches, which consider plant architecture explicitly, might support and facilitate these approaches [10,12-14]. The class of functional-structural plant models explicitly combines plant architecture and plant functioning. They have proven useful for analysing feedback processes between plant architecture and physiological processes, if local environmental conditions are the key process drivers [15-18]. A milestone for modelling plant architecture of grapevine is the work of Louarn et al. [19] and Louarn et al. [20] on TopVine. Their statistical approach for a static architectural model of grapevine was based on digitised real plants. This approach allowed integrating inter-plant variability. The variability was mimicked for basal positions of the shoot, parameters for the spatial paths of the shoots and leaf azimuth and elevation angles, whereas each shoot has the same leaf area, which is a model input, and the length of each sub-unit is the same. TopVine was used to simulate light-sensitive differences in canopy structure variability within and between cultivar $\times$ training system pairs for Grenache Noir and Syrah [20]. A similar study of Iandolino et al. [21] aimed at simplifying simulations of grapevine canopy reconstruction. Random sample measurements in the field and in the lab were used to parameterise allometric relationships, which serve as input for YPLANT, a statistical plant generator. YPLANT reconstructs static plants with option for high variability and estimations of light distributions within the virtual canopy. Recent modelling studies, which also aim at including knowledge on grapevine architecture, either are developments of the TopVine-approach or are based on greenhouse grapevine fruiting cuttings trained to one shoot axis as model plant ([22], GrapevineXL). Prieto et al. [23] modelled intra-canopy variability of gas exchange by considering leaf nitrogen content and local acclimation to radiation in grapevine. Here, the static model for one digitised plant from the TopVine study was used and adapted to match the leaf size of Syrah. Garin et al. [24] used an architectural dataset from TopVine to set up a first dynamic grapevine model used to analyse the development of powdery mildew within the virtual grapevine canopy. The dynamic approach was implemented based on $L-P y$, a programming language for Lindenmayer-systems. One of the latest functional-structural models for grapevine was designed to simulate berry quality based on carbon and water fluxes (e.g., [22,25,26], for GrapevineXL). This was achieved by linking a biomechanical gas exchange model and a complex water status model to local plant architectural conditions. Here, the model for plant architecture was simplified and descriptive to mimic the conditions of greenhouse grown grapevine fruiting cuttings of 
Cabernet Sauvignon. Just recently, the leaf-based functional-structural plant model HydroShoot was published [27], focusing on simulations of leaf gas-exchange rates in complex canopies by coupling hydraulic, energy and exchange modules. It was exemplarily evaluated using static mock-ups of virtual grapevine canopies to study plant-scale gas-exchange rates and leaf-scale temperature and water potential in response to canopy architecture.

In summary, grapevine architecture models could be promising tools to predict the impact of rising temperatures on canopy structure of grapevines, and thus provide the basis for the simulation of canopy management techniques under future climatic conditions. However, this requires an appropriate consideration of the variability in the grapevine canopy architecture, modelling approaches for the temperature-responsiveness of morphological processes and the sensitivity of the virtual crop to management measures such as shoot positioning. With this study, we wanted to highlight possible effects of temperature conditions on architectural traits of growing grapevine canopies using historical weather data. The aim was to show that a simple, descriptive dynamic three-dimensional model for grapevine architecture can be used to mimic effects of changing temperatures on canopy growth in a typical Riesling vineyard.

\section{Materials and Methods}

First, we developed a simple, descriptive, but dynamic three-dimensional model for grapevine architecture, which is able to simulate the natural variability of a growing canopy in a typical Riesling vineyard (Rheingau, Germany) including the responsiveness to shoot positioning. Data of digitised grapevines were used for model conceptualisation and parameterisation. Second, this model was extended to cope with the temperature-sensitivity of morphological processes such as bud break and organ growth. Third, we ran simulations studies for Riesling growth and development under different historical temperatures to assess the integrated temperature-effect on canopy level and compared canopy architectures under different climates.

\subsection{Field Site}

Vines for digitisation were grown in the VineyardFACE field experiment located at Hochschule Geisenheim University in the Rheingau region, Germany $\left(49^{\circ} 59^{\prime} \mathrm{N}, 7^{\circ} 57^{\prime} \mathrm{E}\right)$. The region has a moderate oceanic climate with an average temperature of $10.5^{\circ} \mathrm{C}$ and annual rainfall of $543 \mathrm{~mm}$. The experimental vineyard was planted in 2012 with Vitis vinifera L. cv. Riesling (clone 198-30 Gm) grafted to rootstock SO4 (clone $47 \mathrm{Gm}$ ) with at a vine spacing of $0.9 \mathrm{~m}$ and a row spacing of $1.8 \mathrm{~m}$ and a north-south row orientation. The soil at the field site is characterised as a sandy loam. Soil management consisted of alternating row of open soil and a grass mixture cover crop. The cover crop was mulched several times during the vegetation period. Integrated plant protection was carried out according to the code of good practice. Vines were cane pruned and trained to a single Guyot vertical shoot positioning system (VSP) with one cane pruned to approximately ten nodes (Figure 1). After bud break, shoot number was adjusted to eight shoots per vine. Vineyard area was 0.5 ha $\left(5000 \mathrm{~m}^{2}\right)$, within which a free air $\mathrm{CO}_{2}$ (FACE) enrichment system was installed. Details of the FACE system have been published elsewhere $[28,29]$. 


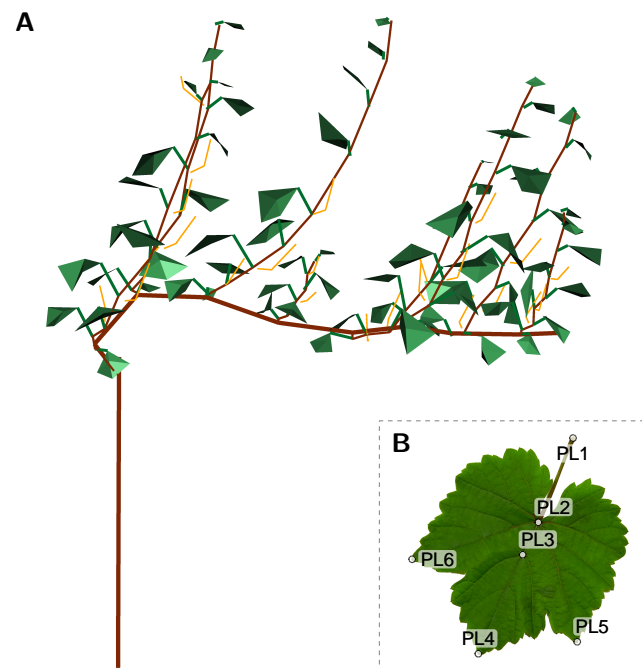

Figure 1. (A) Exemplary early-stage reconstructed digitised vine showing vine structure with single Guyot vertical shoot positioning system (VSP) with one cane pruned to approximately eight nodes (green: leaves; yellow: flowers; brown: cane/shoot); and (B) Riesling leaf digitisation scheme.

\subsection{Plant Digitisation}

All shoots from three grapevines were digitised at three developmental stages on 3-4 May 2018, 17 May 2018 and 7-8 June 2018, corresponding approximately to E-L stages 12 (5 leaves expanded), 15 (8 leaves expanded), and 26 (cap fall complete), respectively (see Coombe [30] for E-L Stages). The three-dimensional structure of the canopy was recorded using an electromagnetic 3D-digisiter ("Fastrak", Polhemus, Colchester, U.S.). Kahlen and Stützel [31] and Schmidt and Kahlen [32] described the general digitisation procedure. The specific digitisation protocol applied to the grapevines took into account the topological relationships between main organs, and was designed to allow the reconstruction of the guyot cane, primary shoots, lateral shoots, leaves and flowers. For digitisation, the transmitter, which generates the measurement sphere and includes the origin of the Cartesian coordinate system, was placed at a distance of $1 \mathrm{~m}$ to the canopy at cane level, with the $x-, y$ - and $z$-axes pointing towards the canopy, parallel to the row and vertically, respectively. All metallic objects within a $3 \mathrm{~m}$ radius of the transmitter were removed to avoid inferences with the electromagnetic sphere. Digitisation started at the cane level, at which all nodes were digitised with one point per node, taken in the axil of each node, irrespectively of bearing a shoot or not. On a node bearing a shoot, the shoot was digitised, before digitisation continued along the cane. For shoot digitisation, all primary nodes of the shoot, beginning at the base and moving towards the apex, were recorded with one point at the bud axil. For each node, all leaves, flowers and lateral shoots emanating from the node were digitised according to the following sequences. Flowers were digitised with three points: PF1 was set at the branching point of the flower towards the shoot apex. PF2 was set at the first branching point of the flower itself towards the flower tip. PF3 was the tip of the flower itself. Leaves were digitised with six points. PL1 was set at the petiole base towards the shoot apex (Figure 1). PL2 was the leaf base, recorded at the adaxial side of the leaf. PL3 was the joining point of the midrib and the veins spanning the central lobe of the leaf, taken on the adaxial side. PL4 was the tip of the mid rip. PL5 and PL6 were the tips of the veins spanning the middle lobes to the left and the right side (seen from leaf base to tip) of the central lobe, respectively. Lateral shoots were digitised in the same way as primary shoots. Apical nodes of primary or lateral shoots with less than $1 \mathrm{~cm}$ of length and leaves with less than $3 \mathrm{~cm}$ of primary vein length were not digitised.

\subsection{Weather Data}

Weather data for model parameterisation during the 2018 season were collected from a weather station located at the experimental site. Historical weather data from 1927 to 2018 (91 years) were 
provided by Germany's National Meteorological Service (DWD) from a station located approximately $200 \mathrm{~m}$ from the experimental site (Station-ID: $1580,49^{\circ} 59^{\prime} \mathrm{N}, 7^{\circ} 57^{\prime} \mathrm{E}, 110.2 \mathrm{~m}$ above NN).

We used daily mean $T_{m}\left({ }^{\circ} \mathrm{C}\right)$, minimum $T_{\min }\left({ }^{\circ} \mathrm{C}\right)$ and maximum $T_{\max }\left({ }^{\circ} \mathrm{C}\right)$ temperatures as estimated by the respective DWD standards. This includes slight adaptations of the methodology; for instance, between 1935 and 1986, $T_{m}$ was calculated based on three measurements per day $(7,14$, and $21 \mathrm{MOZ})$ as $T_{m}=\left(T_{7}+T_{14}+T_{21} \cdot 2\right) / 4$, while since 2006 at least 21 hourly measurements were used in an arithmetic mean calculation. This slightly different estimation throughout the historic time frame should not be of any concern for our simulation results, as these data were exemplarily used to compare different climates.

Selection of candidate years followed the principle of using some of the most distinct years. As a first basis, we categorised by annual mean temperature $\left(\bar{T}_{m, \text { anno, }}{ }^{\circ} \mathrm{C}\right)$, selecting the year with the lowest $\left(1940, \bar{T}_{m, \text { anno }}=8.3^{\circ} \mathrm{C}\right)$ and the highest $\left(2018, \bar{T}_{m \text {,anno }}=12.4^{\circ} \mathrm{C}\right)$ mean temperature. Grouping years in blocks of 10 based on $\bar{T}_{m \text {,anno }}$ we selected the year 1987, as the coldest year of the second block, i.e., the eleventh coldest year, with $\bar{T}_{m, \text { anno }}=9.2^{\circ} \mathrm{C}$. In addition, we selected 2014 as the year with the earliest predicted bud break (day of year (DOY) 99 ; see Section 2.4.1), 1979 with the latest bud break (DOY 135) and, finally, 2017, as the immediate predecessor of the measurement year 2018. More details to specific ranks of $\bar{T}_{m, \text { anno }}$ and bud break BB (DOY) for the selected years are provided in Table 1 and Figure 2.

Table 1. Selected years with ranking position (1-91) for annual average of daily mean air temperature $\left(\bar{T}_{m, \text { anno }}\right)$ and estimated bud break date (BB) $\left({ }^{1}\right.$ - BB for 2018 is based on phenological observations instead of thermal time data; see Section 2.4.1).

\begin{tabular}{ccccc}
\hline & \multicolumn{2}{c}{ Air Temperature } & \multicolumn{2}{c}{ Bud Break } \\
Year & Ranking & $\overline{\boldsymbol{T}}_{\boldsymbol{m} \text {,anno }}\left({ }^{\circ} \mathbf{C}\right)$ & Ranking & BB (DOY) \\
\hline 1940 & $\mathbf{1}$ & 8.3 & $\mathbf{1 1}$ & 122 \\
1979 & $\mathbf{1 5}$ & 9.4 & $\mathbf{9 1}$ & 135 \\
1987 & $\mathbf{1 1}$ & 9.2 & $\mathbf{2}$ & 120 \\
2014 & $\mathbf{9 0}$ & 12.0 & $\mathbf{1}$ & 99 \\
2017 & $\mathbf{8 3}$ & 11.3 & $\mathbf{4 6}$ & 101 \\
2018 & $\mathbf{9 1}$ & 12.4 & $\mathbf{5 1}$ & $111^{1}$ \\
\hline
\end{tabular}

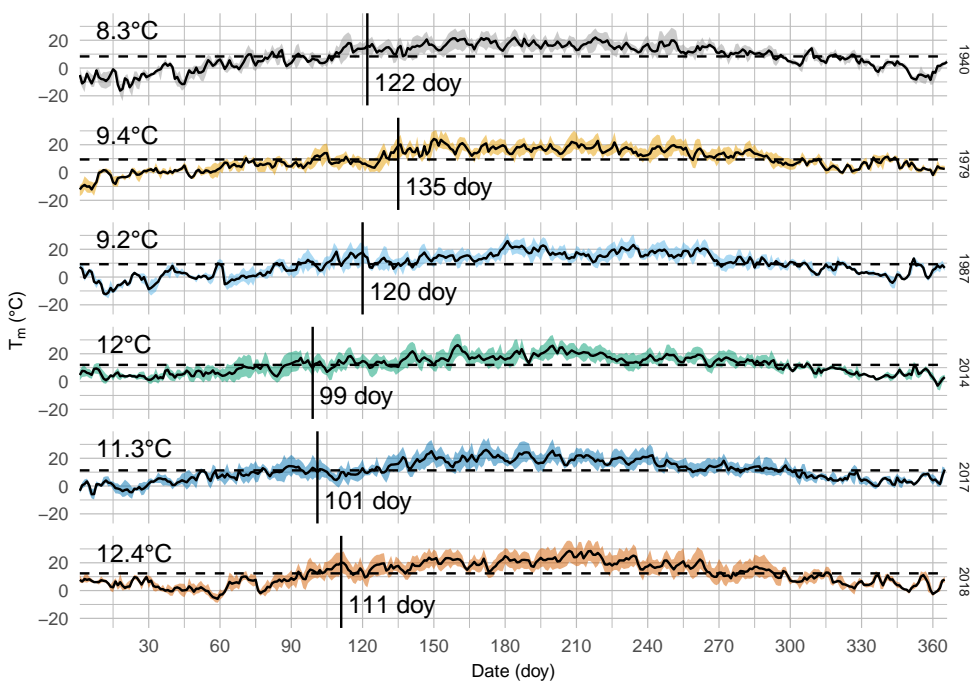

Figure 2. Annual cycle of mean air temperature $\left(T_{m}\right)$ for selected years $(1940,1979,1987,2014,2017$, and 2018) with their respective bud break date (vertical bar) and annual mean temperature ( $T_{m, \text { anno; }}$; dashed line). Ribbon range illustrates daily temperature range (min, max). 
The years selected for the simulation study were 1940, 1987, 2014, 2017 and 2018. We only used the 2018 on-site measurements for model parameterisation (thermal time estimations), while the simulations solely used the historical weather data.

\subsection{Data Analysis}

Data analyses were conducted within $R$ (v3.6.0) [33] using the package rstanarm (v2.17.4) [34] for Bayesian analysis and lme4 (v1.1-21) [35] for (non-)linear mixed models.

\subsubsection{Bud Break}

Phenological data were gathered during 2018 starting at DOY 109 (19 April) following the modified E-L-stage scoring by Coombe [30], where Stage 4 represents the bud break. For practical reasons and with the aim to only estimate average bud burst, shoots were selected totally at random, hence no information on bud position on cane was available. To estimate the variability of bud break with respect to thermal time $\left(\mathrm{THT},{ }^{\circ} \mathrm{C}\right.$ d), thermal time was estimated following the approach of Schultz [36] as

$$
\mathrm{THT}=\sum_{i=1}^{n} \frac{\left(T_{\max , i}-T_{\min , i}\right)}{2}-T_{b}
$$

with a base temperature of $T_{b}=10^{\circ} \mathrm{C}$ and depending on daily maximum $T_{\max }$ and minimum $T_{\min }$ temperatures only; and $n$ stands for days considered in THT summation. Applying a Bayesian linear mixed model to predict the most probable THT-value for the E-L-Stage 4, i.e., the bud break date, while controlling for replications (blocks) and plants (repeated measures) the posterior predictive bud break date was estimated to DOY 111 (21 April). For considering variability around predicted bud break dates with respect to THT, we used the estimated posterior predictive standard deviation of $\sigma_{\mathrm{THT}, \mathrm{BB}}=12.38^{\circ} \mathrm{C}$ d.

Prediction of bud break dates for all other years were realised applying a model from Nendel [37]. Nendel [37] used the single triangle algorithm from Zalom and Goodell [38] for calculation of degree-days $D\left({ }^{\circ} \mathrm{Cd}\right)$,

$$
D= \begin{cases}0 & \text { for } T_{0} \geq T_{\max } \\ \left(\frac{T_{\max }-T_{0}}{2}\right) \cdot\left(\frac{T_{\max }-T_{0}}{T_{\max }-T_{\min }}\right) & \text { for } T_{\min }<T_{0}<T_{\max } \\ T_{m}-T_{0} & \text { for } T_{0} \leq T_{\min }\end{cases}
$$

depending on the daily maximum $T_{\max }$, mean $T_{\mathrm{m}}$, and minimum temperature $T_{\min }$. For our predictions, we set $T_{0}$ to $5.9^{\circ} \mathrm{C}$, the estimated threshold temperature for Riesling bud break in Germany [37]. Beginning with 1 March the degree-days, $D$, were summed until the respective bud-break threshold $D_{\mathrm{BB}}=(186.1 \pm 24.7){ }^{\circ} \mathrm{C} \mathrm{d}$ was reached [37]. For the virtual plant simulations, we used the average date within the date range as the bud break date (BB, DOY). This information was used together with the in situ estimated standard deviation $\left(\sigma_{\mathrm{THT}, \mathrm{BB}}\right)$ to model bud break and its natural variability.

For the bud break prediction for years different from 2018 we always used thermal time (THT) estimated by Equation (1) starting with the respective bud break date.

\subsubsection{Phytomer Appearance}

To model phytomer appearance rate $\mu$ (phytomers $/{ }^{\circ} \mathrm{Cd}$ ), we used the maximum rank for each digitised primary shoot and the corresponding thermal time of the measurement date (Figure 3). Using a linear mixed effect model controlling for data from the same plants and repeated measurements in time, we found $\mu=0.0453$ phytomers $/{ }^{\circ} \mathrm{Cd}$ or in other words the necessary thermal time for the development of a new phytomer is $1 / \mu=22.0892{ }^{\circ} \mathrm{C}$ d. For the lateral shoots, we assumed equal development rates. 


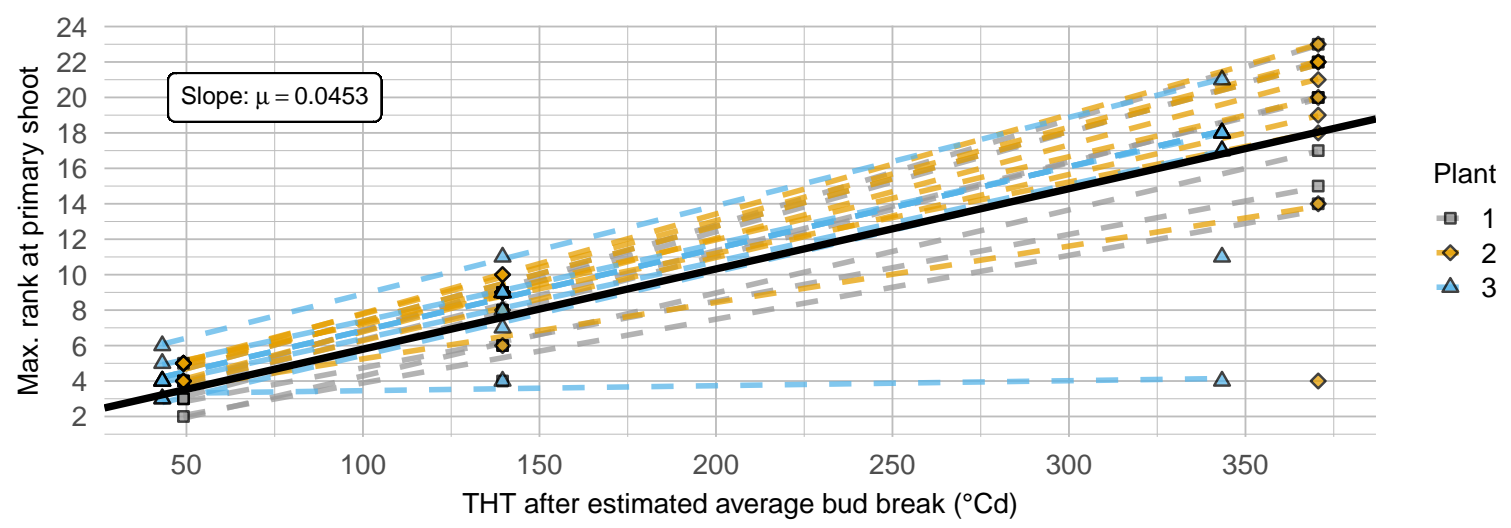

Figure 3. Estimation of phytomer appearance rate $(\mu)$ as the slope of linear mixed model fit.

\subsubsection{Internodes}

Phytomer appearance rate was used to estimate the thermal time age (THTage, ${ }^{\circ} \mathrm{Cd}$ ) of each node at the different measurement dates. This information was combined with the corresponding primary internode length $\mathrm{IL}_{1}(\mathrm{~cm})$, estimated as the Cartesian distance between two node coordinates, to fit asymptotic growth curves through the origin, following

$$
\mathrm{IL}_{1}\left(R, \mathrm{THT}_{\text {age }}\right)=\mathrm{IL}_{1, \max }(R) \cdot\left(1-\exp \left(-\exp \left(k_{\mathrm{IL}_{1}}\right) \cdot \mathrm{THT}_{\text {age }}\right)\right),
$$

with the growth constant $k_{\mathrm{IL}_{1}}=-3.1812$ and an asymptotic value, i.e., the maximum internode length $\mathrm{IL}_{1, \max }$, that was found to be dependent on the node's rank $(R)$ at the primary shoot. We found the $\mathrm{IL}_{1, \max }$ coefficients for the different ranks to follow a repetitive sequence for higher ranks, while for lower ranks $(R \leq 7)$ a simple linear increase in $\mathrm{IL}_{1, \max }$ with rank fitted the data well (Figure 4 ).

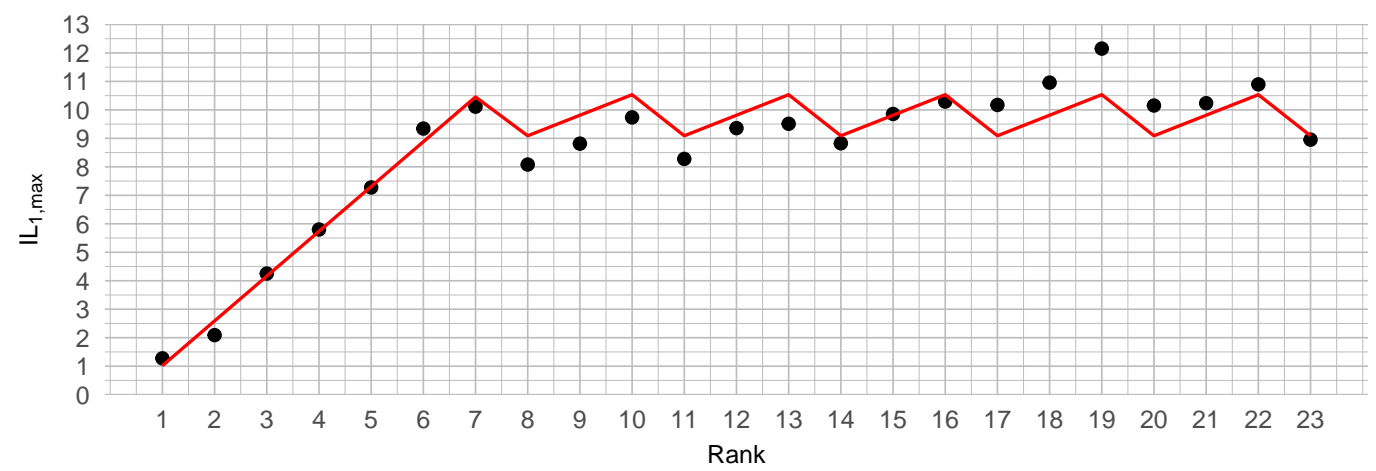

Figure 4. Estimated coefficients (dots) for rank wise maximum internode length $\left(\mathrm{IL}_{1, \max }\right)$ and model fit (red line, Equation (4)).

Hence, a step-function (Equation (4)) was used to model this systematic:

$$
\mathrm{IL}_{1, \max }(R)=\left\{\begin{array}{ll}
R \cdot a_{1}+b_{1} & R \leq 7 \\
((R+1) \bmod 3) \cdot a_{2}+b_{2} & \text { else }
\end{array},\right.
$$

with $a_{1}=-0.5562, b_{1}=1.5729$ and $a_{2}=0.7212, b_{2}=9.0909$.

Model curves versus measurement data are shown in Figure $5 \mathrm{~A}$ indicating good model performance even for higher ranks, where only sparse measurement data were available.

A similar approach was applied for lateral internode length $\mathrm{IL}_{2}(\mathrm{~cm})$, which is calculated as

$$
\mathrm{IL}_{2}\left(R, \mathrm{THT}_{\text {age }}\right)=\mathrm{IL}_{2, \max }(R) \cdot\left(1-\exp \left(-\exp \left(k_{\mathrm{IL}_{2}}\right) \cdot \mathrm{THT}_{\text {age }}\right)\right),
$$


with $k_{\mathrm{IL}_{2}}=-3.9706$. In this case, the asymptotic values $\mathrm{IL}_{2, \max }$ showed no sign of a distinct repetitive sequence at higher levels, hence a asymptotic growth model was used to model rank dependency (Equation (6)),

$$
\mathrm{IL}_{2, \max }(R)=b_{3}+\left(a_{3}-b_{3}\right) \cdot \exp \left(-\exp \left(k_{\mathrm{IL}_{2, \text { max }}}\right) \cdot R\right),
$$

with the coefficients $k_{\mathrm{IL}_{2, \max }}=-0.1183, a_{3}=-2.4822$ and $b_{3}=9.4788$. Model fit versus data is given in Figure $5 \mathrm{~B}$ showing sparse data availability at ranks above four.

To account for variability in lateral shoots regarding appearance probability and time of a lateral bud break, locations (rank) of lateral shoots and their respective frequency at this location were extracted from the digitised plant data (Figure 6). The appearance probability $P_{\mathrm{app}, 2}(-)$ was calculated as the quotient of the number of lateral shoot at a specific rank and the total count of this rank $\left(n_{R, \text { tot }}=50\right)$, equal to the number of digitised shoots. As the development of lateral shoots was not yet completed at the final measurement date, we assumed a maximum appearance probability of $98 \%$ for $R>7$.

A

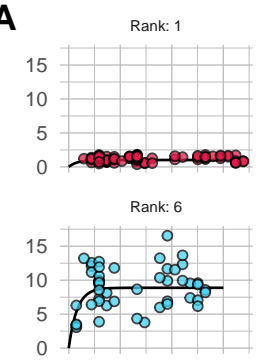

Rank: 11

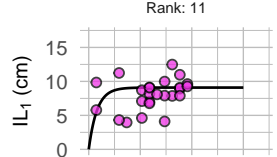

Rank: 16

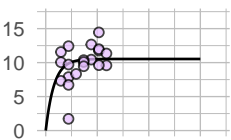

Rank: 21

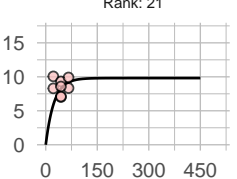

$150 \quad 300 \quad 450$
Rank: 2

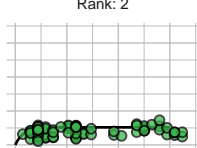

Rank: 7

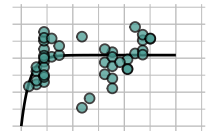

Rank: 12

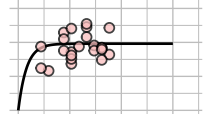

Rank: 17

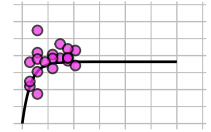

Rank: 22

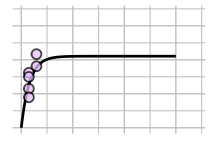

$\begin{array}{lll}150 \quad 300 & 450\end{array}$

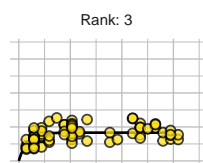

Rank: 8

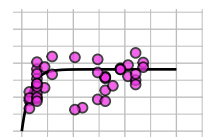

Rank: 13

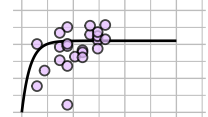

Rank: 18

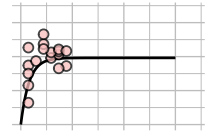

Rank: 23

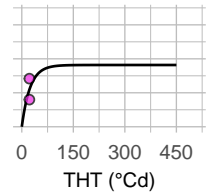

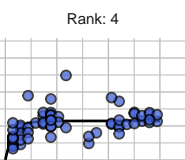

Rank: 9

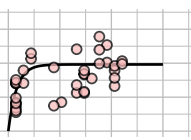

Rank: 14

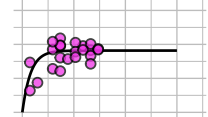

Rank: 19

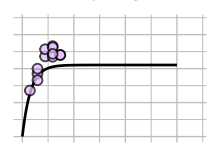

$0 \quad 150 \quad 300 \quad 450 \quad 0 \quad 150 \quad 300 \quad 450$

\section{-Model}

- Measurement

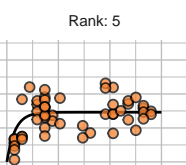

Rank: 10

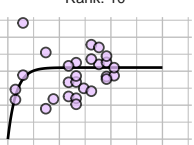

Rank: 15

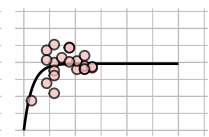

Rank: 20

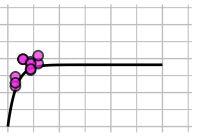

B
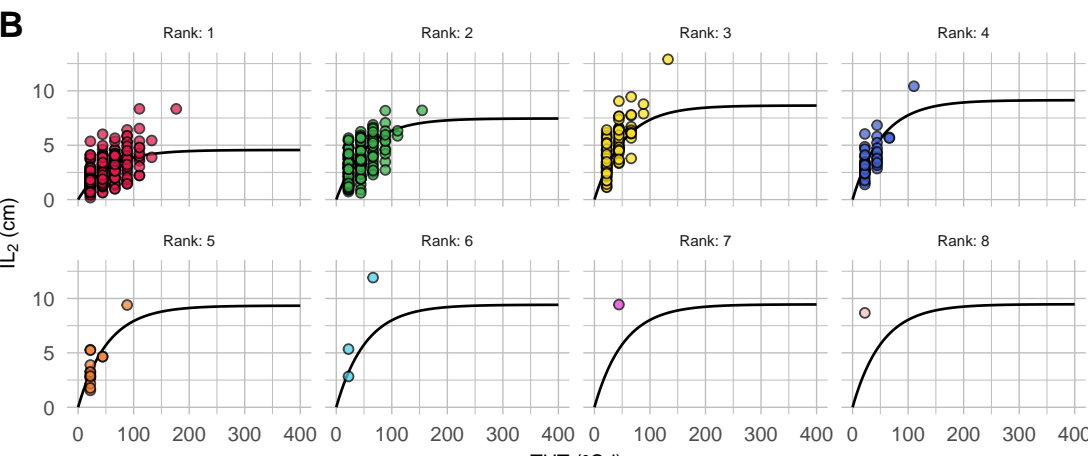

Rank: 6

Rank: 7

Rank: 8
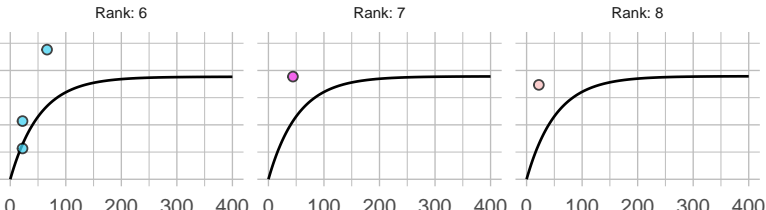

THT $\left({ }^{\circ} \mathrm{Cd}\right)$

Figure 5. Model fit (solid line) and measurement data (circles) for internode length over thermal time: (A) internodes of primary shoots, where colours indicate different model coefficients, showing the repetitive pattern (equal colours) at ranks $R>7$ (Equation (4)); and (B) internodes of lateral shoots, where colours indicate different model coefficients (ranks). 


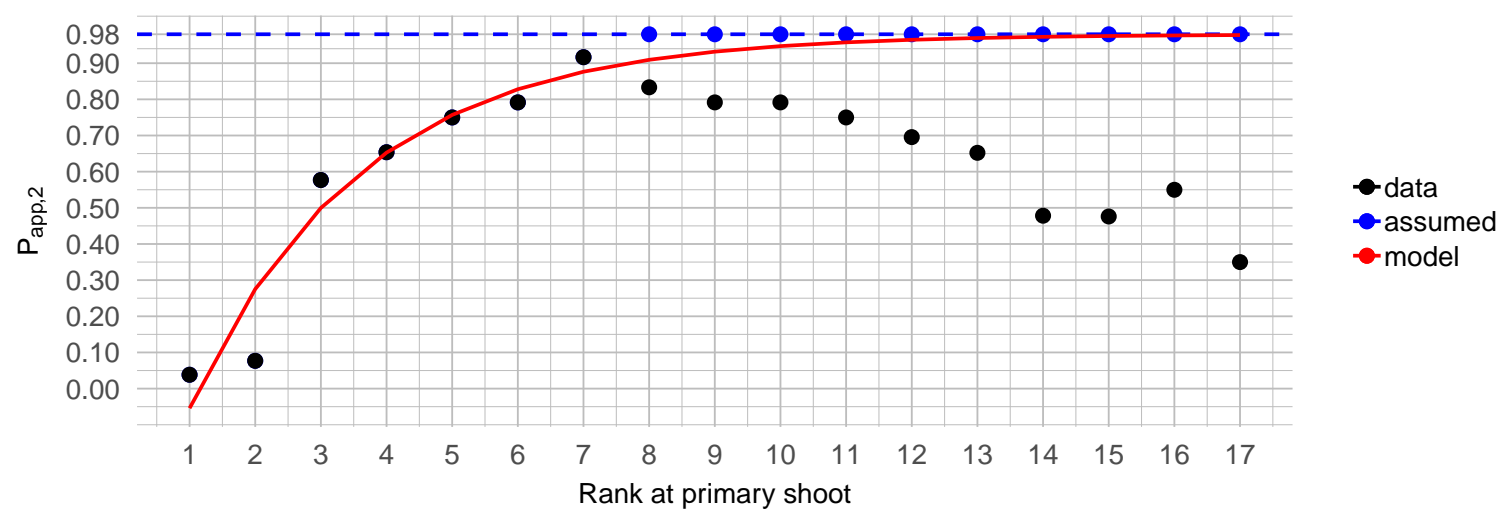

Figure 6. Estimated appearance probability for lateral shoots $P_{\mathrm{app}, 2}$ (black dots) at specific ranks and model fit (red line, Equation (4)). Blue dots represent assumed maximum probability for not yet fully developed ranks at the measurement dates.

Using this dataset, an asymptotic function was fitted describing the appearance probability at different ranks, as follows:

$$
P_{\text {app }, 2}(R)=p_{0}+\left(p_{1}-p_{0}\right) \cdot \exp \left(-\exp \left(k_{P_{\mathrm{app}, 2}}\right) \cdot R\right)
$$

with $p_{0}=0.9800, p_{1}=-0.5376$ and $k_{P_{\text {app }, 2}}=-0.9585$.

Lateral bud break from a primary shoot's node was modelled as a thermal time (THT) after appearance of the corresponding rank (Equation (8)). Based on the previous analysis and on expert opinion, Ranks 1 and 2 were excluded from the analysis, i.e., lateral shoots only grow from Rank 3 upwards. Furthermore, an outlier with a negative THT was excluded, too, leaving 23 primary shoots with a total of 236 lateral shoots within the analysis.

A linear function was fitted to predict necessary post-appearance THT at which the lateral bud break occurs $\left(\mathrm{THT}_{\mathrm{BB}, 2},{ }^{\circ} \mathrm{C}\right.$ d) at a specific rank. This accounts for the observation, that the first lateral shoots did not appear from the lowest ranks, even after excluding the first two ranks. Model fit was realised with a Bayesian mixed effect model to control for sampling structure, i.e., measurements from the same plant or the same shoot, and to estimate a posterior predictive standard deviation to be used as an uncertainty measure in the predictions of $\mathrm{THT}_{\mathrm{BB}, 2}$. Best fit to the linear function,

$$
\operatorname{THT}_{\mathrm{BB}, 2}(R)=q_{0}+q_{1} \cdot R \text { for } R>2,
$$

was found for the coefficients $q_{0}=337.0334$ and $q_{1}=-18.5344$. Average posterior predictive standard deviation of $\mathrm{THT}_{\mathrm{BB}, 2}$ across ranks was estimated to $\sigma_{\mathrm{THT}, \mathrm{BB}, 2}=27.98^{\circ} \mathrm{C}$ d. Since this linear model would allow for negative $\mathrm{THT}_{\mathrm{BB}, 2}$, i.e., lateral shoots would start growing from a bud not yet present, we limited the earliest thermal time passed after bud appearance to $\mathrm{THT}_{\mathrm{BB}, 2, \min }=3 \cdot \frac{1}{\mu}=66.2676^{\circ} \mathrm{C} \mathrm{d}$. This represents the state that a lateral shoot appears at the earliest when three further buds are present at the primary shoot. It is based on data from lateral shoots growing from Rank 17, the highest rank a lateral shoot was already present during the experimental time frame (data not shown). Hence, implementation of this limitation follows:

$$
\mathrm{THT}_{\mathrm{BB}, 2}(R)=\max \left(\mathrm{THT}_{\mathrm{BB}, 2, \min } q_{0}+q_{1} \cdot R\right) \quad \text { for } R>2,
$$

while this correction was applied twice-before and after sampling from a Gaussian normal distribution with mean $\mathrm{THT}_{\mathrm{BB}, 2}$ and standard deviation $\sigma_{\mathrm{THT}, \mathrm{BB}, 2}$ (Figure 7). 


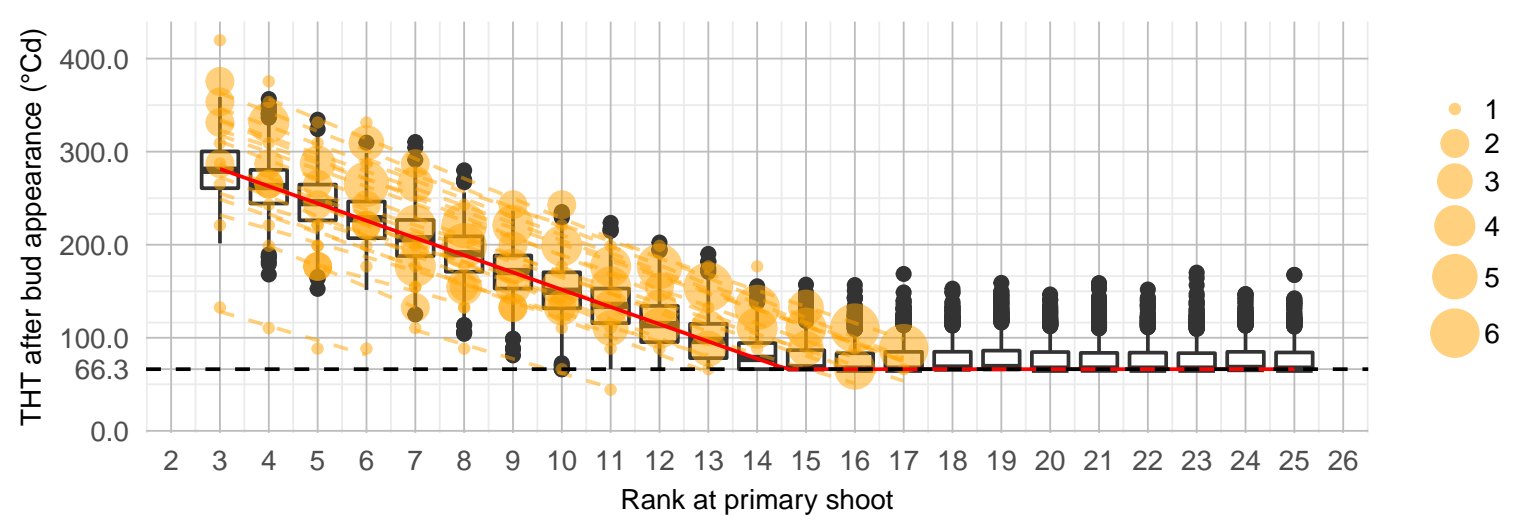

Figure 7. Data (orange) and model (red) to describe lateral bud break as thermal time (THT) after primary bud evolution. Box plots are results of sampling $(n=1000)$ from a Gaussian normal distribution around the mean $\left(\sigma_{\mathrm{THT}, \mathrm{BB}, 2}=27.98003\right)$ after correcting for minimal $\mathrm{THT}_{\mathrm{BB}, 2, \min }=$ $66.2676229^{\circ} \mathrm{Cd}$.

Cane internodes were initialised in the simulation scene using the maximum internode length of a full-grown primary shoot $\left(\mathrm{IL}_{1, \mathrm{max}}\right)$, as this matches the applied training system, where one primary shoot was used as the cane in the next season.

\subsubsection{Leaves}

The landmark definition for digitising leaves already considered a model to estimate leaf area (LA, $\left.\mathrm{cm}^{2}\right)$ utilising only the sum of the length's of the two secondary leaf veins $\left(L_{2 \mathrm{nd}}, \mathrm{cm}\right)$, e.g., as proposed by Beslic et al. [39] for a different variety of Vitis vinifera L. (cv. Blaufränkisch) (Equation (10)).

$$
\sqrt{\mathrm{LA}}=s_{\mathrm{LA}} \cdot L_{2 \mathrm{nd}}
$$

The model was parameterised using two-dimensional vein measurements of 302 Riesling leaves and their respective leaf area (LI-3100C Area Meter, LICOR) provided by Döring et al. [40], leading to a scaling factor of $s_{\mathrm{LA}}=0.6869294$.

The sum of the length's of the two secondary leaf veins $\left(L_{2 n d}\right)$ in our digitised data is given by Equation (11):

$$
L_{2 \text { nd }}=\overline{\text { PL2, PL5 }}+\overline{\text { PL2, PL6 }} \text {. }
$$

where $\overline{\text { PL2, PL5 }}$ and $\overline{\text { PL2, PL6 }}$ are measured as Cartesian distances between two landmarks (Figure 1).

Following this approach to describe leaf size, our leaf growth model was set up for the sum of the secondary leaf veins and using a similar approach as for the internode length. For the primary shoot leaves, $L_{2 n d, 1}$ is modelled as

$$
L_{2 \mathrm{nd}, 1}\left(R, \mathrm{THT}_{\text {age }}\right)=L_{2 \mathrm{nd}, \max , 1}(R) \cdot\left(1-\exp \left(-\exp \left(k_{\mathrm{L}_{2 \mathrm{nd}, 1}}\right) \cdot \mathrm{THT}_{\text {age }}\right)\right),
$$

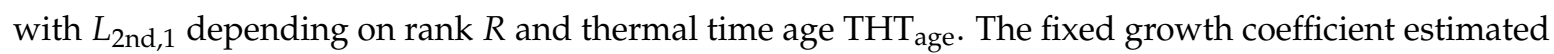
from our digitised plants was $k_{\mathrm{L}_{2 n d, 1}}=-4.1819$ and the asymptotic values $L_{2 \mathrm{nd} \text {,max, } 1}$ were found to be rank dependent, as follows:

$$
L_{2 \mathrm{nd}, \max , 1}(R)=b_{4}+\left(a_{4}-b_{4}\right) \cdot \exp \left(-\exp \left(k_{L_{2 \mathrm{nd}, \max , 1}}\right) \cdot R\right)
$$

with the coefficients $k_{L_{2 n d, \max , 1}}=-0.8131, a_{4}=2.5499$ and $b_{4}=19.7196$.

The sum of the length of secondary veins on lateral shoot leaves $\left(L_{2 n d, 2}\right)$ is modelled by

$$
L_{2 \text { nd,2 }}\left(R, \mathrm{THT}_{\text {age }}\right)=L_{2 \text { nd,max,2 }} \cdot\left(1-\exp \left(-\exp \left(k_{\mathrm{L}_{2 \mathrm{nd}, 2}}\right) \cdot \mathrm{THT}_{\text {age }}\right)\right),
$$


with two constants $L_{2 n d, \max , 2}=11.9418$ and $k_{\mathrm{L}_{2 n d, 2}}=-3.0008$. In this case, no clear dependence of $L_{2 n d, m a x, 2}$ on rank was found; hence, we assumed all leaves on lateral shoots can reach the same maximum size. It should be noted that this assumption was only based on measurements up to Rank 5 ; hence, measurements later in the seasons might have revealed a more diverse pattern.

Petiole length was found to be proportional to leaf size as sum of secondary veins $\left(L_{2 n d, 1}\right)$ and best fit with a second-order polynomial model. Equations (15) and (16) are the results for primary $\left(P L_{1}\right.$, $\mathrm{cm})$ and lateral leaf petiole lengths $\left(P L_{2}, \mathrm{~cm}\right)$ estimated with a mixed model controlling for repeated measurements and sampling structure.

$$
\begin{aligned}
& \operatorname{PL}_{1}\left(L_{2 \mathrm{nd}, 1}\right)=a_{5} \cdot L_{2 \mathrm{nd}, 1}+b_{5} \cdot\left(L_{2 \mathrm{nd}, 1}\right)^{2}, \\
& \operatorname{PL}_{2}\left(L_{2 \mathrm{nd}, 2}\right)=a_{6} \cdot L_{2 \mathrm{nd}, 2}+b_{6} \cdot\left(L_{2 \mathrm{nd}, 2}\right)^{2},
\end{aligned}
$$

with $a_{5}=0.3122, b_{5}=0.0060, a_{6}=0.3247$, and $b_{6}=0.0071$.

Petiole orientation in relation to a shoot follows an alternate-distichous phyllotaxis $[36,41]$ where the petiole is assumed to grow out of the shoot at an angle of approximately $45^{\circ}$. In the model, this initial orientation is adjusted to further match the average horizontal angle found at primary and lateral shoots (Section 2.5.1). For primary shoots, this angle to the horizon was estimated to $\alpha_{\text {Pet }, 1}=40.0441^{\circ}$ (upward) applying an intercept-only mixed effect model controlling for sampling structure and repeated measurements. In the same way, the average angle of lateral shoots was found to be $\alpha_{\text {Pet }, 2}=35.6239^{\circ}$.

For primary leaf's midrib angle in relation to the horizon $\left(\alpha_{\mathrm{Mid}, 1}\right)$ descriptive statistics indicated an interacting dependence on rank and size. This was transferred into a model equation as follows:

$$
\alpha_{\mathrm{Mid}, 1}\left(R, L_{2 \mathrm{nd}, 1}\right)=c_{0}+c_{1} \cdot L_{2 \mathrm{nd}, 1}+c_{2} \cdot R+c_{3} \cdot L_{2 \mathrm{nd}, 1} \cdot R,
$$

with coefficient values of $c_{0}=50.2723, c_{1}=-6.1390, c_{2}=-5.4465$ and $c_{3}=0.4749$. Only measured once, we used an intercept only-model for lateral leaves leading to $\alpha_{\mathrm{Mid}, 2}=-25.0179^{\circ}$.

In addition, we estimated a three-dimensional leaf shape by a generalised Procrustes analysis with the R-package geomorph (v.3.1.1) [42] based on data from 30 randomly selected leaves that were digitised with 18 instead of only 6 landmarks (data not shown). Thus far, the leaf's shape information and its horizontal orientation (midrib) were only used in visualisations and had no effect on the presented results. Hence, we also did not yet consider other leaf orientation angles, i.e. leaf roll angles around the midrib, that would become of interest as soon as plant-light interaction is introduced into the model.

\subsection{Architectural Model of Riesling Canopy Growth}

The architectural model was based on a Lindenmayer model approach [43]. To include variability of architectural traits not only point estimators (single parameters, such as mean data) but also distributions were considered in the developmental rules for organ appearance, orientation in space and growth rates.

\subsubsection{Model Description}

The functional-structural plant model for Riesling (Virtual Riesling) aims at simulating the dynamic growth of Riesling from bud break on the cane until end of flowering. Our modelling approach focusses on the architecture of the canopy, which is influenced by the growth behaviour of the vine, environmental conditions and vineyard management. The model was written in the programming language XL according to the formalism of relational growth grammars (RGG-formalism, [44]), which is a generalisation of Lindenmayer systems [43]; and we used the interactive modelling platform GroIMP (v.1.5) for model development (www.grogra.de/software/groimp) [44]. 
To simulate the three-dimensional architecture of Riesling, all main organs and their topological connections represent the aerial part of the plant. Rules for growth and development were extracted from digitised data (see Section 2.4) and applied in the model.

\subsubsection{Scene}

A virtual vineyard including three Riesling vines in a row, posts and horizontal wires built the initial set-up of a simulation. To match our experimental field conditions, the cane-supporting wires were placed in-between two posts at $70 \mathrm{~cm}$ above the ground. If more than one plant were initiated, the distance between trunks was $\Delta y_{\text {trunk }}=90 \mathrm{~cm}$. The initial stage of each plant in the scene was represented by its trunk and cane. Grapevine genetics controls that winter buds on the cane were located in alternate-distichous phyllotaxis [41]. Thus, the model samples an alternation angle per bud based on a uniformly distributed random variable in an interval of $170^{\circ}$ to $190^{\circ}$ to introduce natural variability. At the beginning of a simulation, primary shoots will emerge from winter buds accounting for the variability of burst day (Section 2.4.1). Later on, lateral shoots evolve from buds on primary shoots. During an entire simulation, virtual plant management included events of shoot positioning (SP) similar to vineyard management practices. A system of two wires, each moving from one side to the posts, was implemented in the model to mimic SP. At each SP event, primary shoots that were long enough to be caught, were relocated between the wires. According to the practice at the experimental site, SP was applied successively at four different heights above the ground $(90 \mathrm{~cm}, 110 \mathrm{~cm}, 140 \mathrm{~cm}$ and $170 \mathrm{~cm}$ ). Two pairs of wires remained on the posts at the heights of $110 \mathrm{~cm}$ and $170 \mathrm{~cm}$, after they were moved from the previous heights at $90 \mathrm{~cm}$ and $140 \mathrm{~cm}$, respectively. A simulation ended when more than $90 \%$ of shoots in the virtual stand reached a height of $2.3 \mathrm{~m}$ above the ground (Figure 8 ).

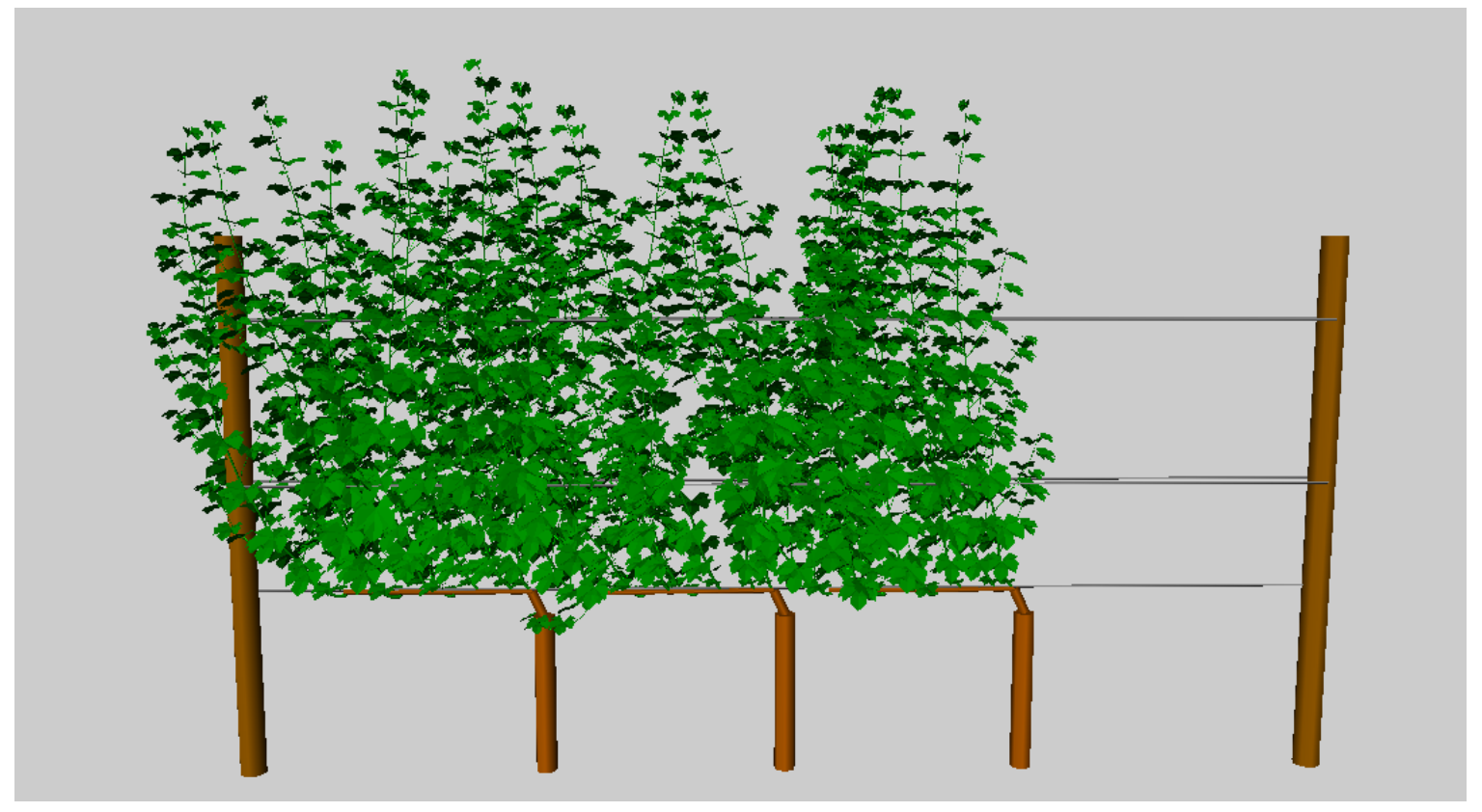

Figure 8. Exemplary end-of-simulation plant architecture including the scene of the Virtual Riesling vineyard section consisting of three plants between two posts and the shoot positioning wire pairs.

\subsubsection{Shoot Development and Growth}

Primary and lateral shoots were built based on phytomers, which differentiated from the apex of a shoot. In the model, a phytomere was the compound of an internode, an axillary bud and a leaf, consisting of a lamina (blade) and petiole. 


\section{Bud Break}

The concept of bud break is described in Section 2.4.1. In brief, to mimic bud break variability of primary buds, we predicted an average day of bud burst on the cane for each year based on the annual temperature cycle and used a standard deviation for bud burst estimated from phenological data of $2018\left(\sigma_{\mathrm{THT}, \mathrm{BB}}\right.$, see Section 2.4.1). Sampling a value of a normal distribution around zero with $\sigma_{\text {THT,ВB }}$ the deviation in thermal time from the predicted average day of bud burst is used to estimate the day of primary bud break for each bud on the cane accordingly. The break of lateral buds on primary shoots depends on a rank-specific probability and a minimum threshold thermal time age (see Section 2.4.3). If a lateral bud is old enough, the chance of burst is checked once, to determine whether a new phytomer appears or the bud becomes inactive.

\section{Phytomers}

The phytomer appearance model multiplies the accumulated thermal time after burst until the current day by $\mu=0.0453$ phytomers $/{ }^{\circ} \mathrm{Cd}$ and divides it by the corresponding rank of the apex (see Section 2.4.3). If the result is equal to or greater than one, a new phytomer appears. At appearance, phytomers are oriented in the three-dimensional space according to the local orientation of the preceding apex. After phytomer emergence from the cane (primary shoot growth) or from the primary shoots (lateral shoot growth), the orientation of the new instance of apex is modified to mimic negative gravitropism. The local orientation of the apex may rotate upwards towards the direction of the vertical of the global coordinate system ( $z$-axis). The rotation angle depends on a parameter for gravitropism strength with values between 0 and 1 . The strength was parameterised to mimic the final shape of primary shoots observed on the digitised plants in the vineyard. Although primary shoots show an upwards orientation, they often do not point straight up. While some shoots grow upwards quickly, others show a clear incline to the cane. Moreover, shoots tend to grow upwards faster the more they are initially pointing downwards (Figure 1). To achieve this natural variability of shapes and growth behaviour, the strength of the negative gravitropism is adjusted to positions of phytomers and the orientation (local z-axis) of the apices. The more an apex points downwards, the stronger it should be rotated upwards. Therefore, the model estimates the apex's orientation as the angle to the $x-y$-plane. If this angle exceeds $-22.5^{\circ}$, the strength increases from 0.5 to 1 with increasing absolute angle to the plane. From $-22.5^{\circ}$ below the plane until an incline above the $x$-y-plane of $45^{\circ}$, the strength is fixed to 0.5 . With an incline equal to or bigger than $45^{\circ}$, the strength is set to the weak value of 0.15 and stays constant.

\section{Internodes}

When a phytomer emerges from the apex, internodes might also be reoriented. While an entire shoot shows an upwards orientation, individual internodes do not consistently follow this trend and they show some variation in orientation from internode to internode. In the model, a slight rotation around the local $x$-axis (sampled from a uniform distribution between $-10^{\circ}$ and $10^{\circ}$ ) modifies the initial orientation of each internode. Internodes of primary and lateral shoots elongate according to Equations (3) and (5) with details described in Section 2.4.3.

\section{Petioles and Leaves}

Petioles first emerge in a fixed yaw-angle of $45^{\circ}$ to their parent internode, in order to maintain the alternating leaf position, before they are adjusted to their final horizontal orientation. The petioles at the experimental site tended to emerge parallel to the global $x$-axis (data not shown), i.e., perpendicular to the row (y-axis), but this depends on the actual orientation of the shoots and can be influenced by the timing of shoot positioning managements with respect to the measurement dates. Hence, we only adjust the petioles horizontal orientation after initialisation. Therefore, the model first projects the petiole on the $x-y$ plane, before adjusting the angle to the $z$-axis. On primary shoots petioles of 
digitised plants were slightly more inclined $\left(\alpha_{\mathrm{Pet}, 1}=40.0441^{\circ}\right)$ than on lateral shoots $\left(\alpha_{\mathrm{Pet}, 2}=35.6239^{\circ}\right)$. Petiole elongation was found to be proportional to leaf growth (see Section 2.4.4).

Along primary shoots leaves at the bottom tend to point downwards, while leaves at the top appear more horizontal (see Equation (17)). Leaf orientation is controlled via the midrib. The model adapts the angles in the same way as the horizontal petiole angles. A fixed midrib angle of $\alpha_{\mathrm{Mid}, 2}=-25.0179^{\circ}$ and hence pointing downwards is used for leaves on lateral shoots. Leaf areas are modelled according to Equations (10), (12) and (14) depending on their order (primary or lateral shoot), rank and thermal time (see Section 2.4.4).

\section{Shoot Positioning}

The model performs shoot positioning automatically up to four times during a simulation. As soon as more than $90 \%$ of primary shoots in the virtual canopy tower over one of the positioning heights, two wires from both sides bend every shoot they catch into the remaining gap. A wire is moved to its final position starting from below the final height on the post (approximately a movement of $45^{\circ}$ upwards) to mimic this manual management practice. This controls whether a shoot is caught by the wires or if it is not affected by shoot positioning. A shoot that has not reached the necessary height for a SP event still might be caught from a wire at the next SP event. The wires get attached to the posts, and, therefore, the extent of the remaining gap between the wires equals the diameter of a post $(10 \mathrm{~cm})$. For SP, the model computes the relation between the number of shoots, that are high enough, and the total number of shoots. If more than $90 \%$ reached or exceeded the corresponding wire height, the model initiates a shoot positioning event by determining the lengths of all shoots, but taking into account the internodes above the cane only. In addition, it subtracts $5 \mathrm{~cm}$ from this shoot's length, since a wire may slide upwards along the shoot during the positioning process and since the trajectory can lead to a too low position in the end. If the resulting value is larger than the height of the wire, the virtual shoot will be caught by the wire and is reoriented as follows: The wire will push the shoot into the centre and induce a reorientation of the shoot. Therefore, we included a joint-command at the position of each node. This command may change the orientation towards the direction of a defined reference point with a defined strength. The reference point is the position on the wire, where the shoot is tucked after the bend. To define its coordinates, the model extracts the $y$-coordinate (along the row) from the first node on the shoot, that is above the final height of the wire. The $x$ - and $z$-coordinates of the reference point are taken from the wire's distance to the middle of the row and the height, respectively. All nodes of a shoot that lie below the reference point, minus a buffer of $5 \mathrm{~cm}$, will be modified. The buffer guarantees that no node is chosen, which would lie above the reference point after the procedure. This is crucial to avoid a downwards reorientation of shoots. Older nodes close to the bottom of a shoot are assumed to be less flexible than younger nodes. Thus, the model modifies younger nodes with higher strength. Additionally, it excludes all nodes from reorientation, that are located more than $50 \mathrm{~cm}$ below the height of the current pair of wires used in the SP event. Using strength and reference point the model can apply the reorientation to all affected nodes. This is a cascade of position modifications, as the change at one node influences positioning of all following objects (Figure 9).

\section{Avoid}

To avoid that organs collide with each other or objects (posts, wires), we implemented a method where nodes change their direction, if obstacles are in their prospective path. Therefore, the model examines if other organs or objects lie within a cone of a certain inner angle and length. If so, the model randomly assigns a new direction within this cone excluding the direction of the detected obstacle (for details, see http:/ / wwwuser.gwdg.de/ groimp/grogra.de/gallery/Technics/smart_line.html). 


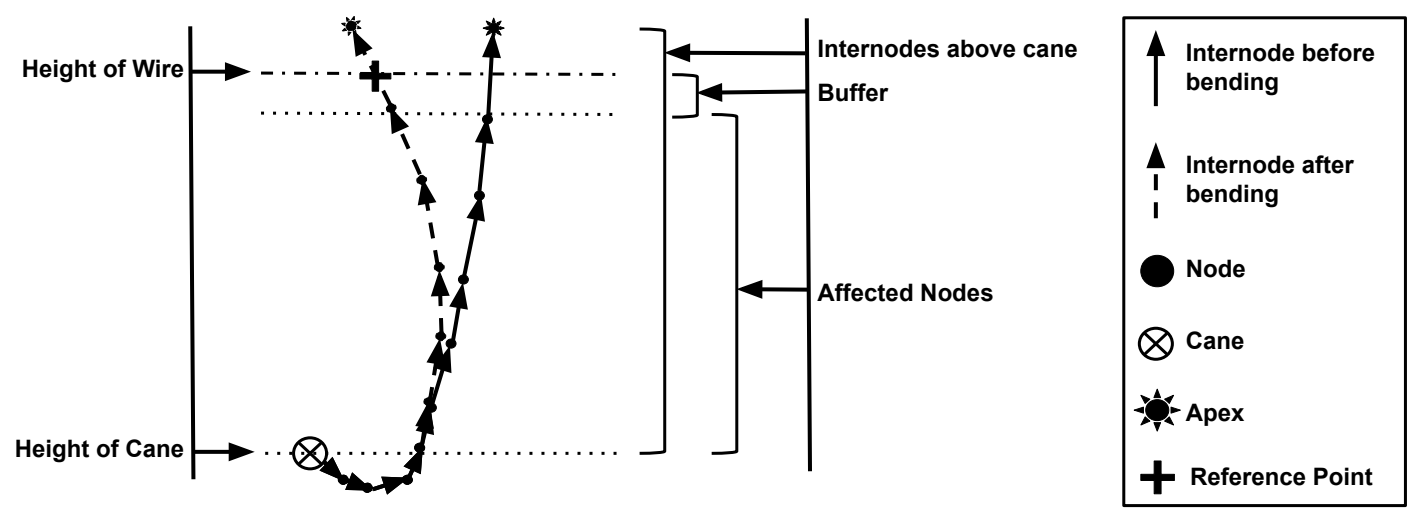

Figure 9. Schematic representation of reorientation of a shoot due to shoot positioning by tucking with a wire: shoot before bending (right); and shoot after bending (left).

\subsubsection{Loop}

Using a semi-stochastic model, i.e., some functions allow for observed variability, multiple simulations of a scenario year are necessary for comparisons across years. Hence, a loop function was implemented to run the model multiple times and automatically printing out internode and leaf data for external post-processing. The output includes the seed value of the random generator to be able to reproduce the exact same growth pattern, whenever needed. Currently, the model resets the scene for multiple simulations after each simulation is completed, i.e., $90 \%$ of the primary shoots within the scene are higher than $2.3 \mathrm{~m}$, and restarts with a new seed value.

\subsection{Simulations}

We set up 2000 simulations per year each with three plants in a single row. Those were run until the threshold for maximum height (foliage cut) was reached. Besides results from the final date we also kept result from DOY 173 , the most frequent end date $(653 / 2000)$ from the reference year 2018 (June 22nd). Effectiveness of sample size to estimate accurate means was tested following an estimation method from Byrne [45]. Using data on leaf area density variability from the final dates of the 2018 simulation with a confidence interval width of $5 \%$ around the mean on a $99 \%$ confidence level, a sample size of $n \geq 434$ was found to be sufficient.

\subsection{Post-Processing}

\subsubsection{Descriptive Statistics}

Descriptive statistics are based on all simulations results ( $n=2000$ per year) and were conducted using $R$ (v3.6.0) [33] in combination with ggplot2 (v3.1.1) [46].

\subsubsection{Leaf Area Density}

Leaf area density (LAD, $\mathrm{m}^{2} \mathrm{~m}^{-3}$ ) was estimated within a representative canopy section of the virtual canopy for each simulation. As a representative canopy section we cut out the central zone of the three-plant canopy. Boundaries of the zone were derived fixing the trunk-base of the central plant to the origin and using the trunk distance of $\Delta y_{\text {trunk }}=0.9 \mathrm{~m}$.

Following the experimental approach of Schultz [47] LAD was estimated for cubes of $0.003375 \mathrm{~m}^{3}$ $\left(a_{\text {cube }}=0.15 \mathrm{~m}\right)$. Hence, the length of the central zone is represented by six cubes while the volume filling process always started with a cube fixed within the bunch zone $(0.85 \mathrm{~m} \geq z \geq 1.15 \mathrm{~m})$ with the cube centre coordinates of $x=0 \mathrm{~m}, y=0.5 \cdot a_{\text {cube }}$ and $z=1 \mathrm{~m}$. Hence, the figures in the results section 
are limited to the transformed canopy section where the origin matches the central coordinate of this initial cube. An exemplary division of the central zone is shown Figure 10.
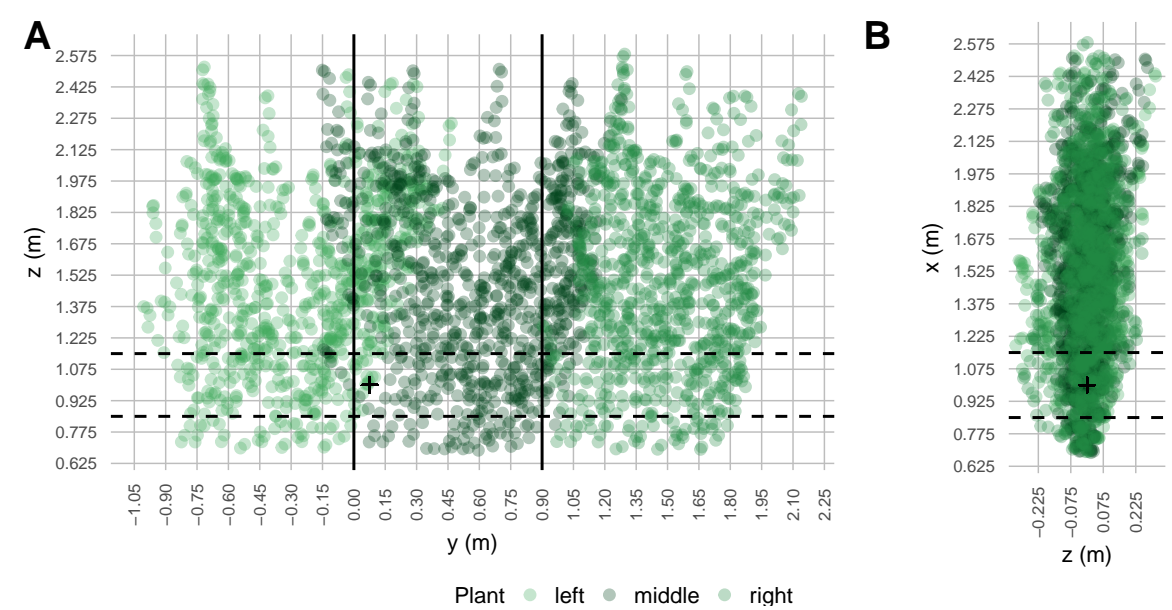

Figure 10. Canopy representation by leaf location points of three simulation plants. Calculations of leaf area density are conducted using the central zone (vertical solid lines, $\Delta y_{\text {trunk }}=0.9 \mathrm{~m}$ (trunk distance)), i.e., a representative canopy section divided into cubes of $0.003375 \mathrm{~m}^{3}\left(a_{\text {cube }}=0.15 \mathrm{~m}\right)$ (dashed line: bunch zone $(0.85 \mathrm{~m} \geq z \geq 1.15 \mathrm{~m})$; + : centre point of initial cube): (A) side view; and (B) backward view.

\section{Results and Discussion}

\subsection{Thermal Time Course}

Selection of historical growth seasons was based on the fixed parameters annual mean temperature and bud break date aiming for a diversified architectural development between years. As grapevine growth was modelled in dependence of accumulated thermal time, we first compared the average thermal time course for all simulation years (Figure 11) based on average bud break and simulation end dates of the 2000 simulations per year. Figure 11 shows that daily THT contributions during the selected years differed in volatility and absolute values, leading to different simulation durations (see also Table 3).

For example, although 2017 was on average a warmer year, a cold period with no THT contribution led to longer simulations when compared to the on average colder years 1940 and 1979. In addition, Figure 11 confirms that simulation duration depended on total accumulated THT (approximately $500^{\circ} \mathrm{Cd}$ ) (see also Figure 14). This was expected, as the end of simulation depended on the plants overall development (shoot height), which in turn depended on THT. As a consequence, this supports the necessity for conducting future climate predictions with this model to not only consider the average global warming, but also the effect on extreme temperature events.

In the following, we go into more details on how our Virtual Riesling vine model reacted to these different seasonal climates. 

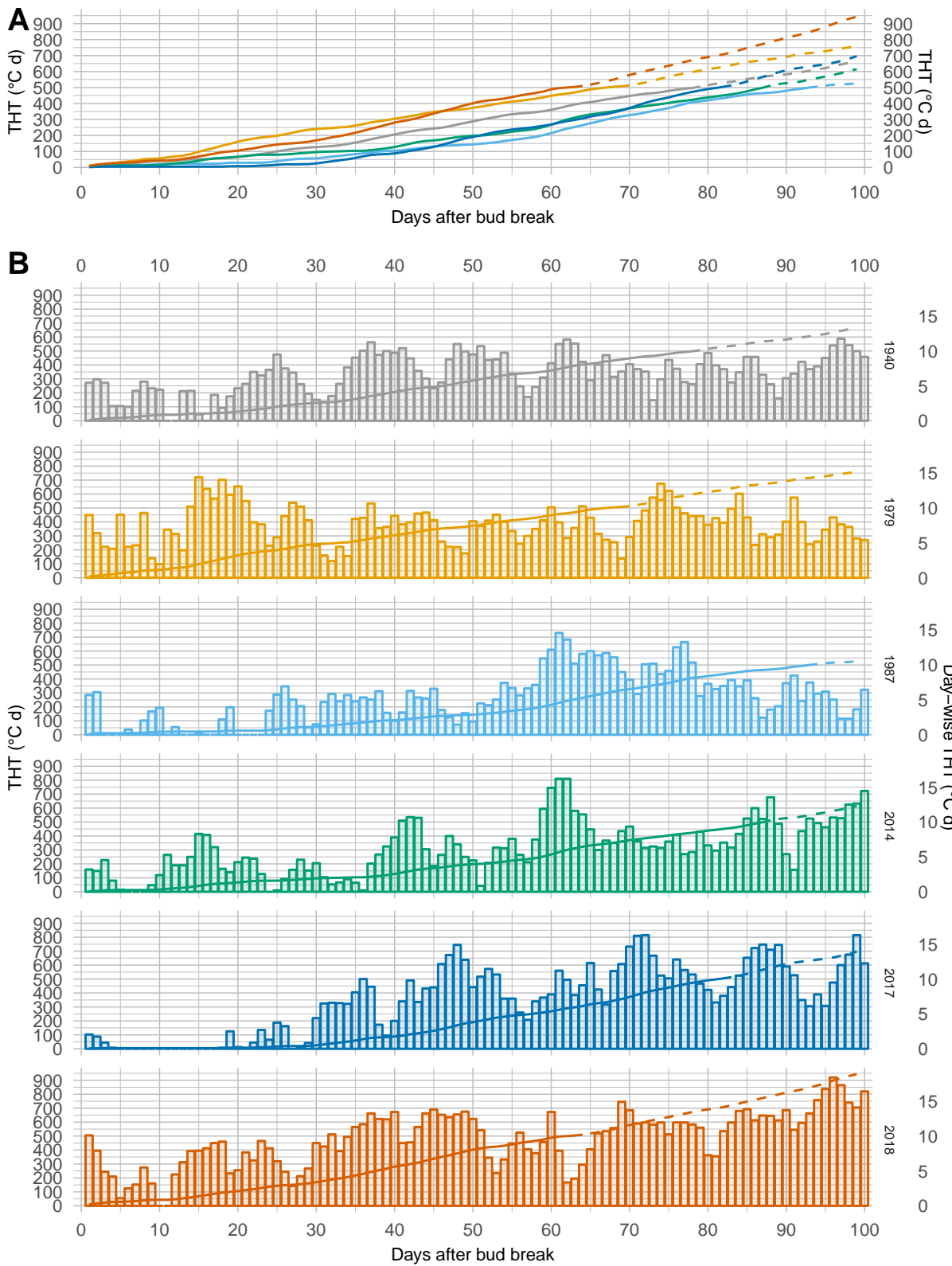

曰1940日1979日1987日2014日2017日2018

Figure 11. Thermal time (THT) development for simulations years: (A) direct comparison of thermal time (sum); and (B) year-wise plots including daily THT contributions. Start of dashed lines indicates average end of simulation date per year.

\subsection{Bud Break}

Figure 12 shows similar distributions around the estimated bud break along the cane within years (vertical profile), but high variability between years, i.e., multiple-peak years (1987) versus single-peak years (2018). The retrospectively estimated overall durations for bud break shows large differences from fewer than 20 days in 2018 up to 60 days in 2017 Table 2. Multiple-peak bud break years can be explained by slow and uneven temperature sum development during the bud break phase, as observed in 2017. Phases of mean temperatures below the threshold in the sensitive phase result in gaps between bud break events (e.g., DOYs 105-117 in 2017, Figure 11) and low average mean daily THT indicate long durations (Table 2). In contrast, distinct single-peak appearances of bud break days can be explained by a compact phase of high mean temperature around the estimated day of bud break (e.g., 1940 and Table 2). The simulated mean bud break data (Table 2) were in good 
accordance with historical data obtained from a long-term collection of Hochschule Geisenheim (e.g., http://rebschutz.hs-geisenheim.de/klima/witterung.php?Auswahl=Weinjahr). The data on interval estimates are, however, difficult to validate due to a lack of historical data of bud break variability. The earlier on-set of bud break in the more recent years is line with the observed shift towards warmer springs [48]. Considering the expected increased variability in weather events with more extreme events [49], we might speculate that the variability from single to multiple primary bud break events will be maintained, but that the general expectation interval for BB predictions has to be increased.

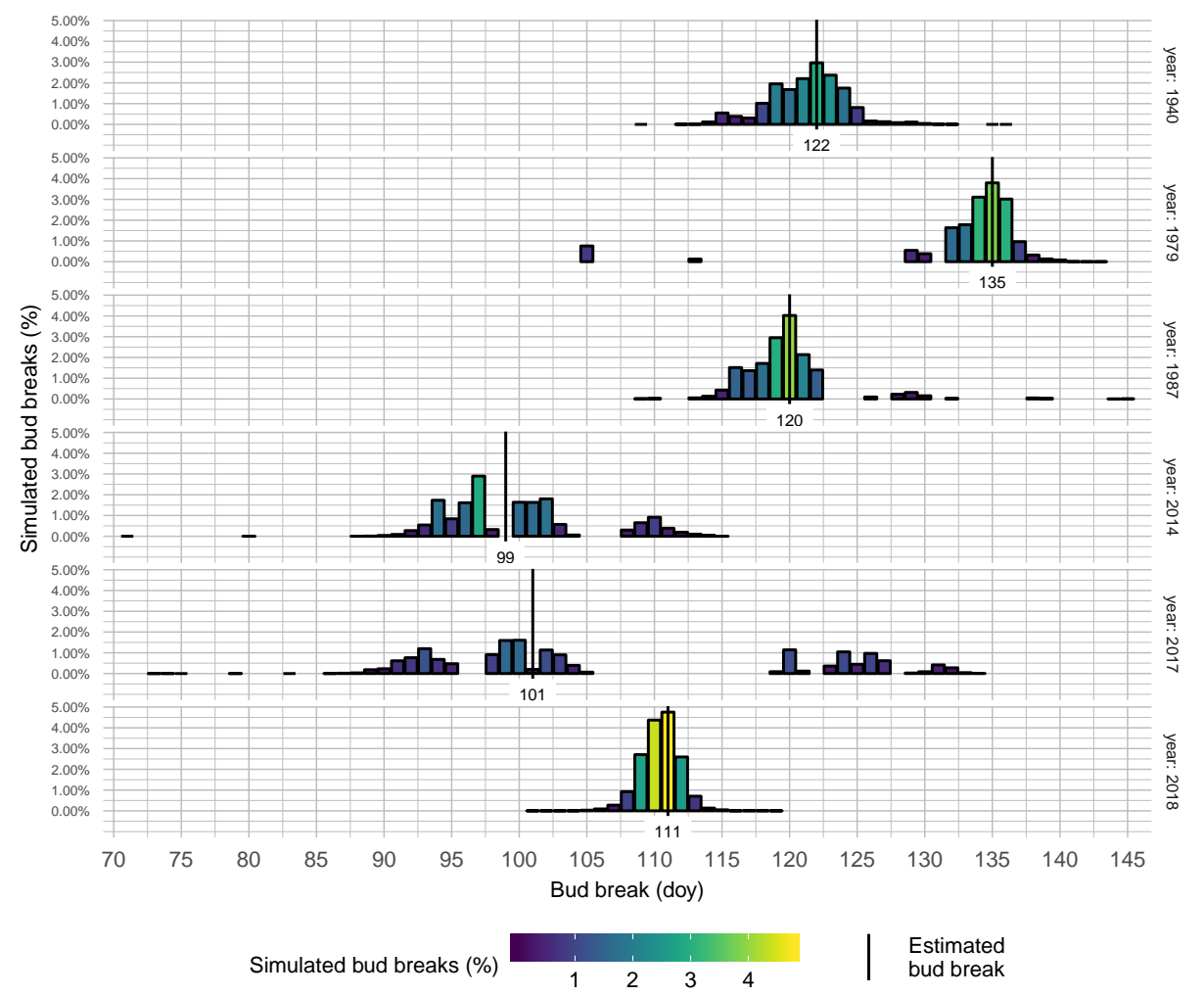

Figure 12. Distribution of simulated bud breaks at day of year (DOY) for all simulations $(n=2000$ per year; 2000 simulations $\times 3$ plants $\times 8$ shoots $=48,000$ simulated bud breaks per year).

Lateral bud break shows similar patterns over years and ranks (Figure 13). The latter differs significantly from the pattern of bud break for primary shoots. Bud break for lateral shoots clearly shifts in time from lower to higher ranks, which mimics the successive appearance of new phytomers on the primary shoots (see Section 2.4). This shift follows a linear trend for the time periods of lateral bud break with highest density (lighter colours on top of the scatter plots), almost without variability towards earlier DOY, but similar dispersion for phases later than those associated with highest densities. Thus, this linear trend marks an upper limit for the rank-dependent day of lateral bud break caused by the maximal established appearance rate (see Section 2.4). Earlier years show a similar slope in this linear trend, whereas 2017 and 2018 show steeper increases, and thus shorter overall durations. This is associated with the higher mean temperatures of more than $20^{\circ} \mathrm{C}$ during the bud break phase in the latter years versus ca. $18^{\circ} \mathrm{C}$ in earlier years (Table 2). The overall duration for lateral bud break between years varied between 35 in 2017 and 53 in 1979, which can be explained by low high to low average daily mean temperatures and mean daily THT in the corresponding years (Table 2). 


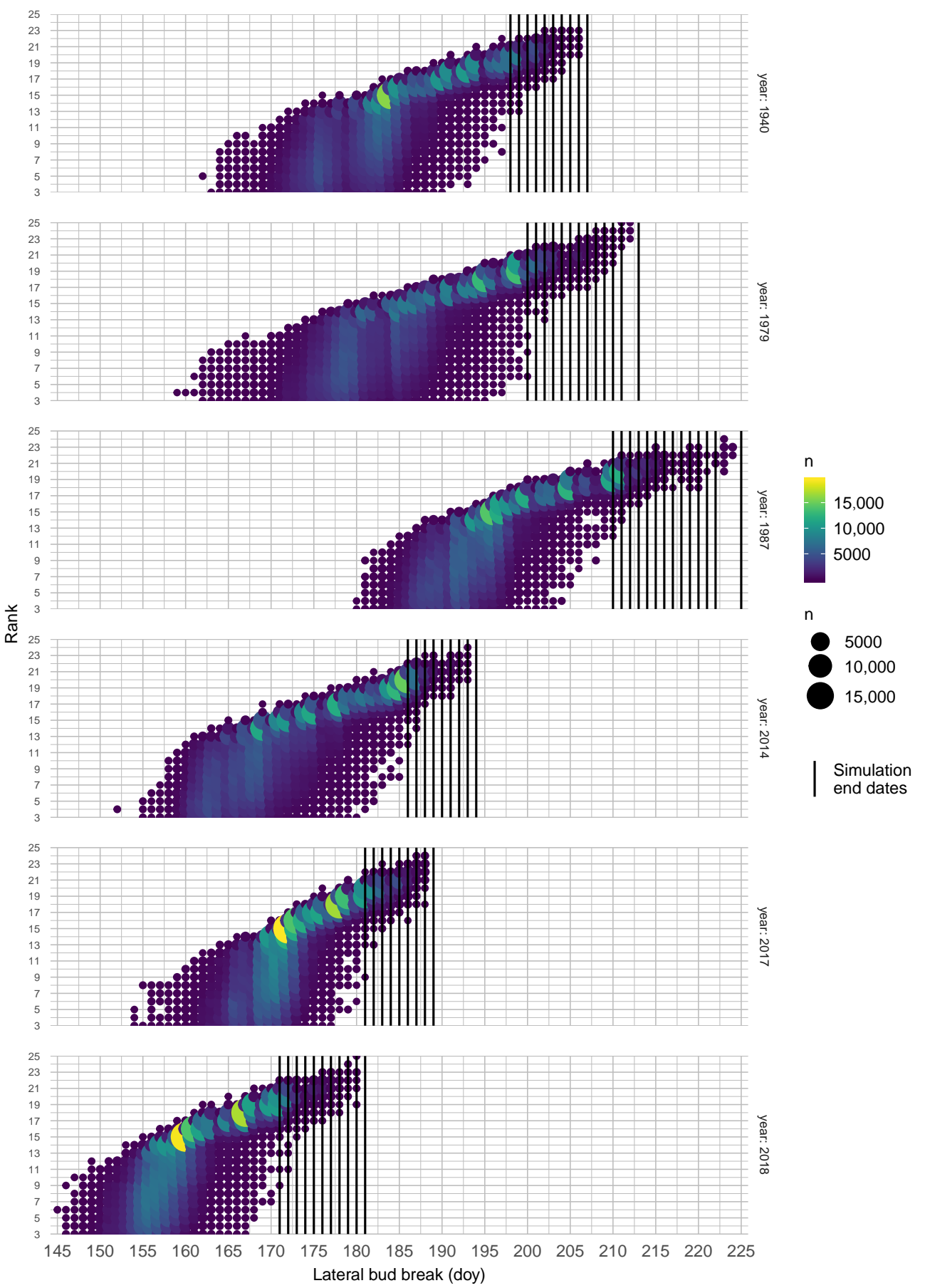

Figure 13. Lateral bud break counts of different ranks at day of year (DOY) for all simulations ( $n=2000$ per year). 
Table 2. Bud break statistics per year: Range of Dates (first $B B_{\min }$ and last $B B_{\max }$ ) and average daily mean temperature $\left(\overline{T_{m}}\right)$.

\begin{tabular}{cccccc}
\hline & Year & $\boldsymbol{B B}_{\text {min }}(\mathbf{D O Y})$ & $\boldsymbol{B B}_{\max }(\mathbf{D O Y})$ & $\overline{\boldsymbol{T}}_{\boldsymbol{m}}\left({ }^{\circ} \mathbf{C}\right)$ & Mean Daily THT $\left({ }^{\circ} \mathbf{C} \mathbf{d}\right)$ \\
\hline \multirow{6}{*}{ Primary } & 1940 & 109 & 136 & $13.7 \pm 2.3$ & $3.8 \pm 2.1$ \\
& 1979 & 105 & 143 & $10.5 \pm 24.6$ & $2.2 \pm 3.1$ \\
& 1987 & 109 & 145 & $11.9 \pm 23.4$ & $2.5 \pm 2.6$ \\
& 2014 & 71 & 115 & $11.6 \pm 23.2$ & $2.3 \pm 2.4$ \\
& 2017 & 73 & 134 & $10.7 \pm 22.5$ & $1.5 \pm 1.9$ \\
Lateral & 2018 & 101 & 119 & $15.5 \pm 22.7$ & $5.4 \pm 2.8$ \\
\hline \multirow{6}{*}{} & 1940 & 162 & 206 & $17.7 \pm 22.4$ & $7.7 \pm 2.1$ \\
& 1979 & 159 & 212 & $17.4 \pm 22.5$ & $7.4 \pm 2.5$ \\
& 2014 & 180 & 224 & $17.8 \pm 23.5$ & $7.9 \pm 3.2$ \\
& 2017 & 152 & 193 & $18.4 \pm 23.0$ & $8.5 \pm 3.0$ \\
& 2018 & 145 & 188 & $20.1 \pm 23.0$ & $10.1 \pm 3.1$ \\
\hline
\end{tabular}

\subsection{End of Simulation}

As expected from the thermal-time based model concept, the different trends in temperatures over the simulation periods did not affect average accumulated thermal time in the different years (Figure 14), e.g., $520^{\circ} \mathrm{C} \mathrm{d}^{-1}$ for 2018 . Small deviations of less than $12{ }^{\circ} \mathrm{Cd}^{-1}$ cover the time for the appearance of just one new phytomer. In contrast, the range of thermal time for reaching the final height differs between 8 and 17 days (Figure 14). Mean DOY for reaching the termination criteria for a simulation describes a time interval of 40 days starting from DOY 174 (Table 3).

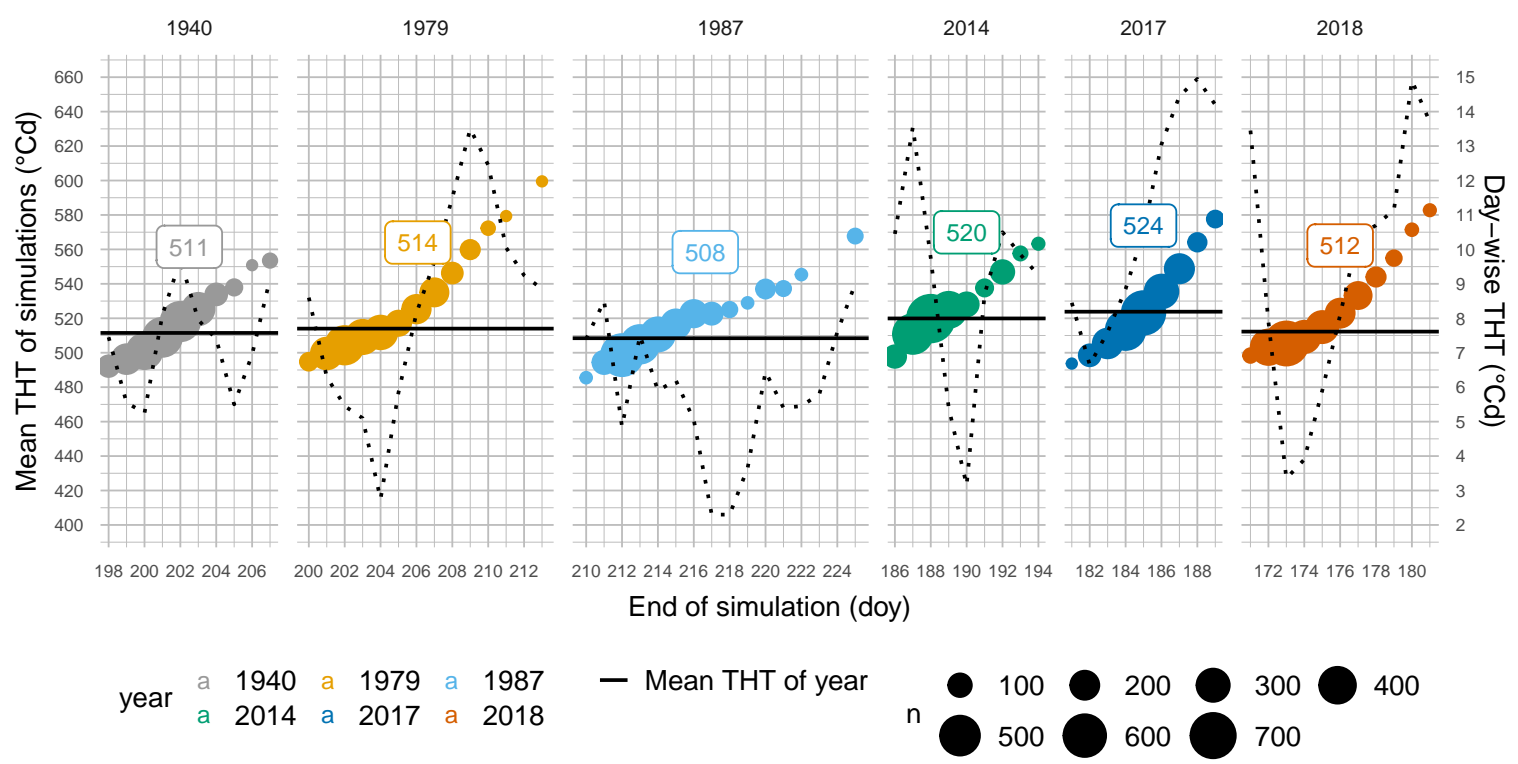

Figure 14. Variability in end of simulation date (DOY) with average accumulated THT per end-date and per year, plus daily THT contributions of adjacent dates.

Our simulations covered the growth period from primary to lateral bud break over the years. Note that the resulting simulation duration was the shortest for 2018 with just 63 days (Table 3). The longest duration was $50 \%$ larger, which means that for 1987 it was predicted to take 94 days until $90 \%$ of the shoots in the virtual stand reach the final height. Mean temperature during the simulation is a good predictor for duration of the considered growth period (linear model with $R^{2}=0.98$ ). However, the stable overall pattern did not predict the year-specific variability of the whole growth period over 
the years, which was also found by Kahlen and Chen [17]. This means that predicting future variability in bud break of grapevine will likely remain a challenging task and deserves further investigations.

Table 3. Average number of leaves in canopy zone $(\Delta y=0.9 \mathrm{~m})$ per year with corresponding mean output date $(90 \%$ Shoot-Height $\geq 2.3 \mathrm{~m})$, mean simulation duration and air temperature during simulations.

\begin{tabular}{ccccc}
\hline Year & $\begin{array}{c}\text { Leaves in Canopy Zone } \\
\text { (mean } \pm \text { sd) }\end{array}$ & $\begin{array}{c}\text { End of Simulation Date } \\
\text { (mean DOY) }\end{array}$ & $\begin{array}{c}\text { Simulation Duration } \\
\text { (mean DOY) }\end{array}$ & $\begin{array}{c}\text { Simulation } \boldsymbol{T}_{\mathrm{m}} \\
\text { (mean } \pm \text { sd) }\end{array}$ \\
\hline 1940 & $917 \pm 108$ & 201 & 79 & $16.5 \pm 3.2$ \\
1979 & $967 \pm 135$ & 204 & 69 & $17.2 \pm 2.9$ \\
1987 & $915 \pm 128$ & 214 & 94 & $15.0 \pm 4.2$ \\
2014 & $978 \pm 130$ & 188 & 89 & $15.7 \pm 3.8$ \\
2017 & $926 \pm 113$ & 185 & 84 & $15.8 \pm 5.4$ \\
2018 & $917 \pm 108$ & 174 & 63 & $17.9 \pm 3.6$ \\
\hline
\end{tabular}

\subsection{Leaf Area}

The variability in reaching the final heights (Figure 14) also affects the mean leaf area per shoot at the end of the simulations (Figure 15). The longer it takes until the final height is reached, the larger is the mean leaf area per shoot. Mean values cover a range from $0.5 \mathrm{~m}^{2}$ to $1.3 \mathrm{~m}^{2}$, which is in the range of typical values for grapevine in the production before the first hedging event. Schultz [36] reported a primary leaf area per shoot of $0.27 \mathrm{~m}^{2}$ in the 1987 growing season for vines bearing 16 shoots. Plants simulated with Virtual Riesling bearing eight shoots per vine reach a primary shoot leaf area of $0.294 \mathrm{~m}^{2}$ in our study (data not shown) at a comparable growth stage with 1987 weather data. Furthermore, Figure 14, on the one hand, shows the limitations of a standard cumulated thermal-time scheme, where more is always more, on the other hand, it illustrates the improvement due to consideration of variability in bud break events (Figures 12 and 13), which allow for reactions on short-term temperature events by altering temperature-related developmental spreads, i.e., time range of end of simulation dates. Figure 15 also shows the dispersion of leaf area over the simulations per output day (day of year). Even though the variability is almost stable over output date and year, it should be considered in further research on the impact of temperatures on grapevine architecture.

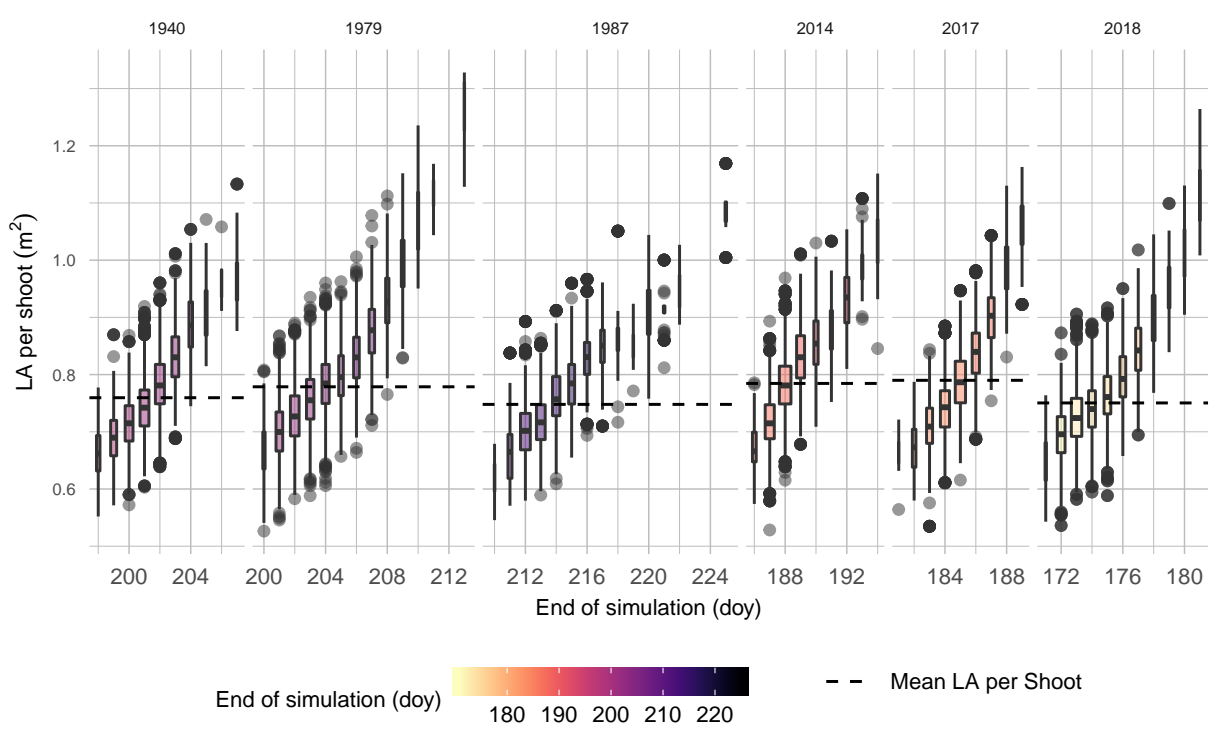

Figure 15. Total leaf area (LA) per shoot at the different end of simulation dates (DOY) for all years. Width of box plots indicate the number of simulations that ended at this date (total number of simulations per year: $n=2000$ ). 


\subsection{Leaf Area Index}

Leaf area index (LAI, $\mathrm{m}^{2} \mathrm{~m}^{-2}$ ) was estimated for the representative canopy using the leaf area data from within $\Delta x=1.8 \mathrm{~m}$ (row distance) and $\Delta y=0.9 \mathrm{~m}$ (trunk distance).

The variability driven spread in reaching the final height translates from shoot leaf area to leaf area index (Figure 16). However, production typical average values are about 3.8 [50].

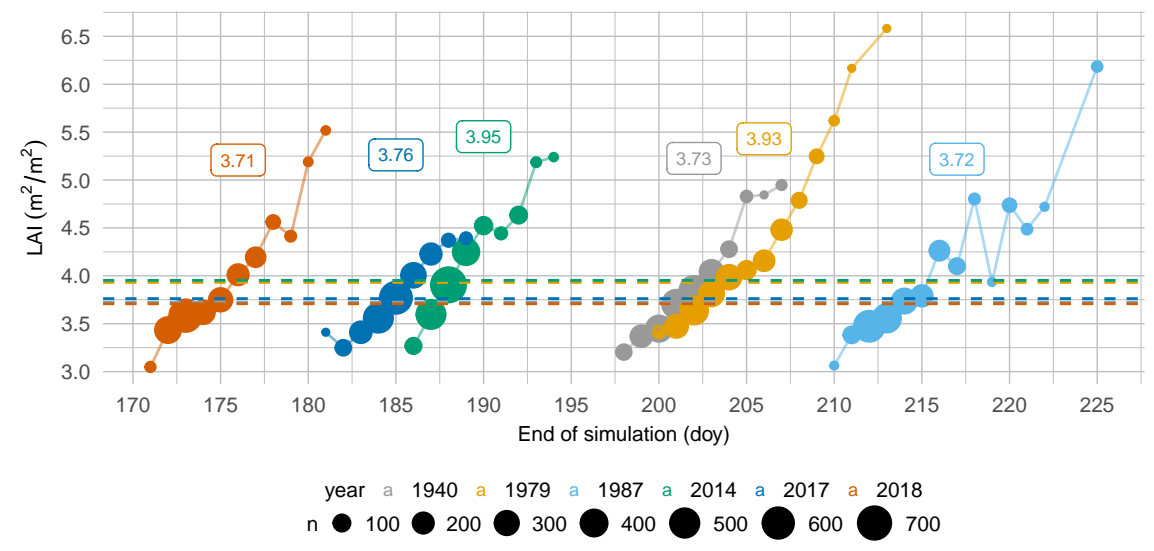

Figure 16. Leaf area index (LAI, $\mathrm{m}^{2} \mathrm{~m}^{-2}$ ) averages per end of simulation (DOY) and year. Dashed lines and annotation indicate year-wise mean LAI.

\subsection{Leaf Area Density}

Leaf area density (LAD, $\mathrm{m}^{2} \mathrm{~m}^{-3}$ ) is an important means to measure the distribution of leaf surface in space and identify locations of elevated density in the canopy [47]. Zones of high density have a higher disease infection pressure due to unfavourable microclimatic conditions [51,52] and contain leaves with a low intrinsic water use efficiency [53]. In addition, high LAD in the bunch zone may lead to a loss of grape quality [54]. LAD can locally reach values of $24 \mathrm{~m}^{2} \mathrm{~m}^{-3}$ in dense canopies [55]. This was the case in our virtual grapevine population, in which the vertical distribution of LAD along the cane $(x=0 \mathrm{~m})$ was similar and seemingly high in all years (Figure 17). LADs of up to $30 \mathrm{~m}^{2} \mathrm{~m}^{-3}$ were observed above the bunch zone in the canopy centre after the last shoot positioning event. Figure 17 shows the distribution of LAD in cubes of $0.003375 \mathrm{~m}^{3}$ located along the cane ( $y$-direction), perpendicular to the row ( $x$-direction) as well as in the vertical direction $(z)$ for all years. Note that LAD about $30 \mathrm{~m}^{2} \mathrm{~m}^{-3}$ does reflect the average presence of circa five fully grown grapevine leaves in a single cube, whereas values of $0 \mathrm{~m}^{2} \mathrm{~m}^{-3}$ indicate that the LAD is positive, but below $0.5 \mathrm{~m}^{2} \mathrm{~m}^{-3}$. Such a low LAD might occur, if in one of ten simulations just one leaf would be positioned in a cube of interest. The high LAD compared to literature data can be explained by the following facts: First, the cubes for the LAD estimations in this study were placed in the middle of the cane, while Schultz [47] placed the cubes to the right and left sides of the cane. Second, a meticulous shoot positioning protocol was observed for the vines used for digitisation, leading to a relatively compact, but slim canopy. Third, as shoot primary leaf area was comparable to previously published data, the high LADs above the bunch zone, as well as the comparatively high LAIs may be explained by a strong side shoot growth. This is underlined by the fact that the main contributor to LAD above the bunch zone were indeed leaves from lateral shoots (Figure 18), while they were leaves from primary shoots in the study of Schultz [47]. This strong lateral shoot growth may on the one hand be related to the very vigorous shoots in our dataset, originating from vines with only eight shoots. On the other hand, it has been shown that, under warm climatic conditions around bud burst, the apical dominance of the shoots is reduced and lateral shoot growth promoted [4]. Thus, a larger dataset for model parameterisation might be necessary to give better estimates of lateral shoot growth under changing climatic conditions. The width of the resulting virtual canopies is represented by the LAD-values for different $x$-positions. Interestingly, the canopy in 1987 has a smaller width than in all other years (Figure 17). This could 
only be explained by the interplay of shoot positioning and the specific pattern of thermal time during the simulation in 1987. Here, on average over all simulations more shoots might have be caught at vertical positioning. Even though the overall width is larger, the differences may not be significant because of the quite low LAD for higher $x$-values. However, the high-resolution of space in cubes can be easily changed to different cubes sizes and thus adapted to specific analytical purposes.

To further analyse these LAD-values, we summarised the data over horizontal layers, i.e., cuboids covering the entire canopy width (Figure 18). The LAD is similar along the cane (y-direction) for all years (Figure 18). Figure 18B shows that layer-specific LAD values are in the range of up to $4 \mathrm{~m}^{2} \mathrm{~m}^{-3}$ at the final simulation days and that this is not affected by the year. In contrast, if LAD data were compared for a specific DOY (here 173), the year and, therefore, temperature would significantly affect leaf area distribution within the canopy in height (z-direction). This has important effects for many viticultural aspects, such as radiation partitioning, cover crop growth, or soil water relations.

In a final coarsening step, LAD of the canopy was estimated depending only on height or width of the canopy using layers of $0.15 \mathrm{~m}$ thickness while differentiating between primary and lateral leaves' LAD (Figure 19). As discussed above, when comparing the end of simulation dates between years, the canopies are more or less similar. Figure 19 shows that the small differences in LAD between years area more related to lateral leaf growth than to primary leaves.

This can be explained by the fact that lateral shoots counts and internodes are rising nearly exponential at thermal times around $500^{\circ} \mathrm{Cd}$, as more and more lateral shoots appear and grow, while the number of primary shoots remains constant. In other studies (e.g., [47]), primary leaves usually dominate LAD instead of lateral leaves, but foliage cut events during the season might have affected this ratio. This discrepancy between our simulations and other findings might be related to the fact, that lateral shoot growth parameterisation of our model was limited to one measurement date per plant. Hence, for instance, we assumed similar phytomer development rates for lateral and primary shoots and did not analyse any effects of possible different phytomer types, as indicated by Figure 4 and identified for other varieties, Grenache Noir and Syrah, by Louarn et al. [56] and Pallas et al. [57]. As a consequence, our model should benefit by a more extensive parameterisation based on digitisations in another, less extreme year and later in the season, ideally immediately before and after a foliage cut.

It is evident that other changing environmental factors, such as $\mathrm{CO}_{2}$ concentration $[28,58]$ and water availability $[59,60]$ will also affect growth and plant architecture of grapevines. Especially growth constraints due to limited water ability drastically affect grapevine shoot architecture (internode length, side shoot growth, leaf size, $[21,61,62])$ and have to be incorporated into descriptive plant architecture models if climate change effects are to be realistically modelled. Water deficit effects on grapevine growth have not yet been integrated into the virtual Riesling, but will be the next step in model development. An additional factor of climate change is the rise of air $\mathrm{CO}_{2}$ levels. Elevated air $\mathrm{CO}_{2}$ concentration might help to alleviate water deficit effects on plant growth due to an increased intrinsic water use efficiency. In addition, changes in $\mathrm{CO}_{2}$ levels will also affect plant architecture [63]. However, results for grapevine are sparse and sometimes contradictory. Greenhouse experiments have shown a reduced growth under elevated $\mathrm{CO}_{2}[61,62]$, while field trials using FACE systems have shown the opposite results $[28,64]$. More research is thus necessary to get reliable field data for modelling $\mathrm{CO}_{2}$ effects on grapevine growth. Modelling future vine growth and canopy characteristics will be of great advantage to vine growers with regards to planning canopy manipulation techniques, optimise plant protection, forecast future workforce demand and facilitate vineyard planning. A faster vegetative development, as seen in Geisenheim in the year 2018, will not only affect grape quality due to higher temperatures and a higher light interception of bunches during berry development, but also challenge viticulturists: As viticultural tasks such as suckering, shoot positioning and hedging will occur in a compressed time frame, workforce demand during the season will change. At the same time, there will be a need to carry out these tasks more accurately to avoid zones with extreme LAD, which favour the development of fungal diseases, especially under warmer conditions. 


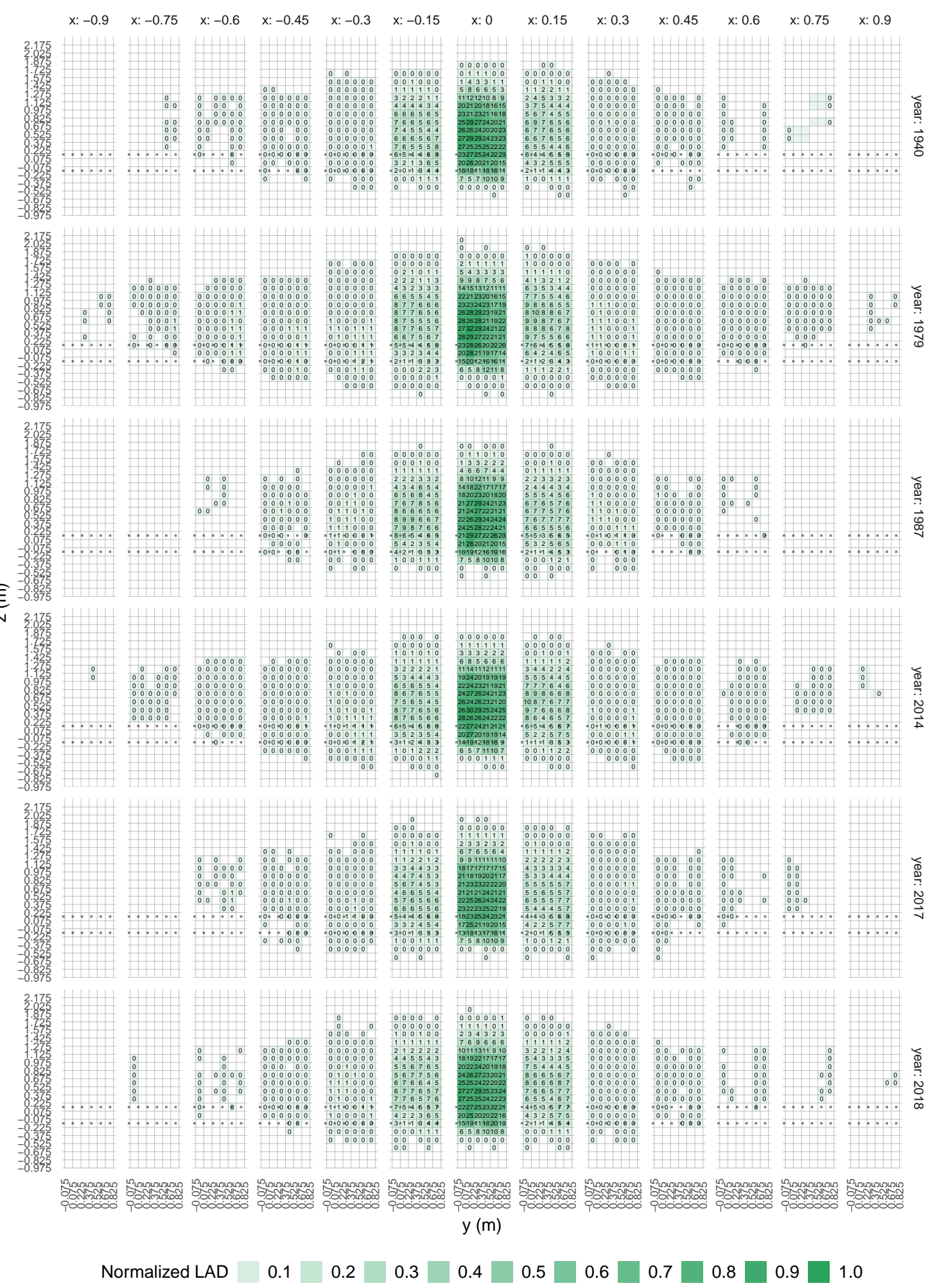

Figure 17. Leaf area density $\left(\mathrm{LAD}, \mathrm{m}^{2} \mathrm{~m}^{-3}\right)$ for cubes of $0.003375 \mathrm{~m}^{3}(15 \mathrm{~cm} \times 15 \mathrm{~cm} \times 15 \mathrm{~cm})$ at final simulation dates (i.e., $90 \% \geq 2.3 \mathrm{~m}$ ) per simulation year. Opacity: normalised LAD (LAD/ $\max (\mathrm{LAD})$; side view of canopy: cane/canopy aligned with $y$-axis; $x$ : distance to cane; $y$ : distance along cane/canopy; $z$ : height relative to centre of bunch zone; dotted line: bunch zone. 
A

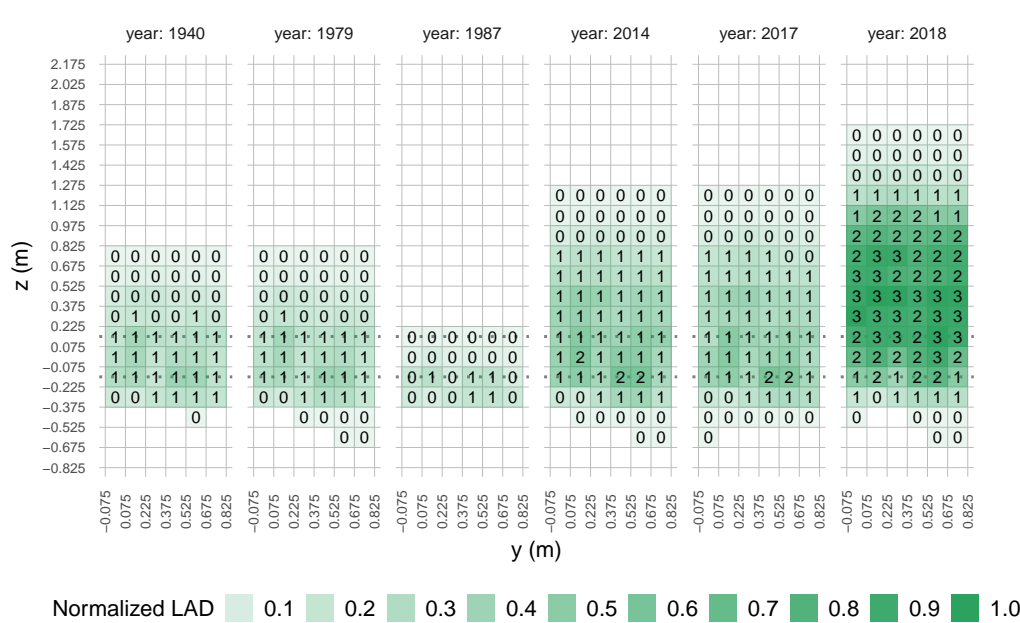

B

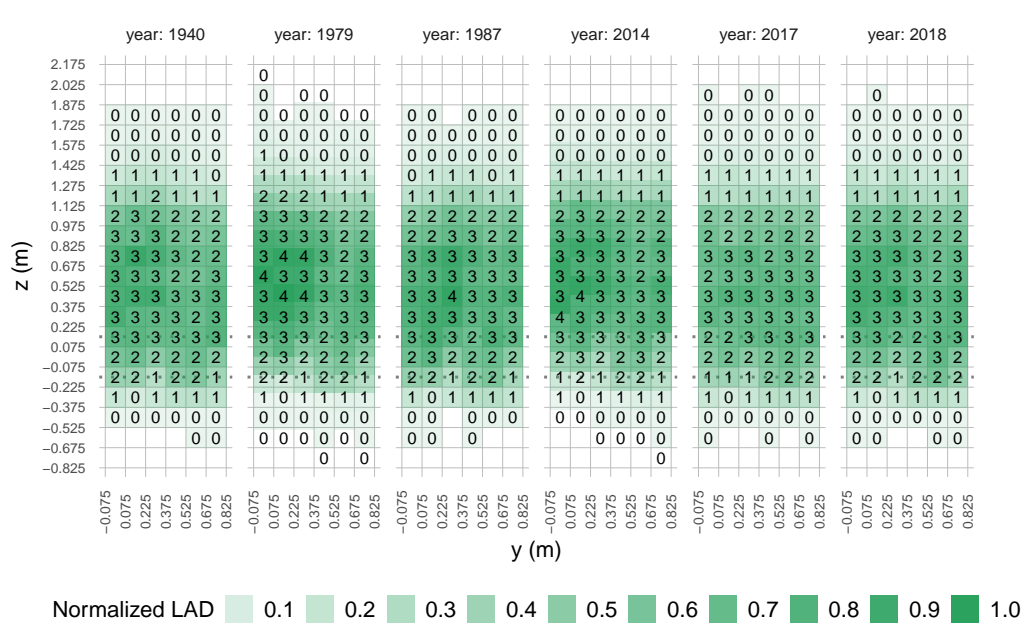

Figure 18. Differences in leaf area density $\left(L A D, \mathrm{~m}^{2} \mathrm{~m}^{-3}\right)$ for cuboids of $0.050625 \mathrm{~m}^{3}(195 \mathrm{~cm} \times 15 \mathrm{~cm} \times$ $15 \mathrm{~cm}$ ) caused by bud burst date and temperatures after bud burst: (A) at DOY 173 per year $\left(n_{2018}=653\right.$, $\left.n_{\text {else }}=2000\right)$; and $(\mathbf{B})$ for averages at the end of simulation per year $(n=2000)$. Opacity: normalised LAD (LAD/ $\max (\mathrm{LAD})$. Side view of canopy: cane/canopy aligned with $y$-axis; $y$ : distance along cane/canopy; $z$ : height relative to centre of bunch zone; dotted line: bunch zone.
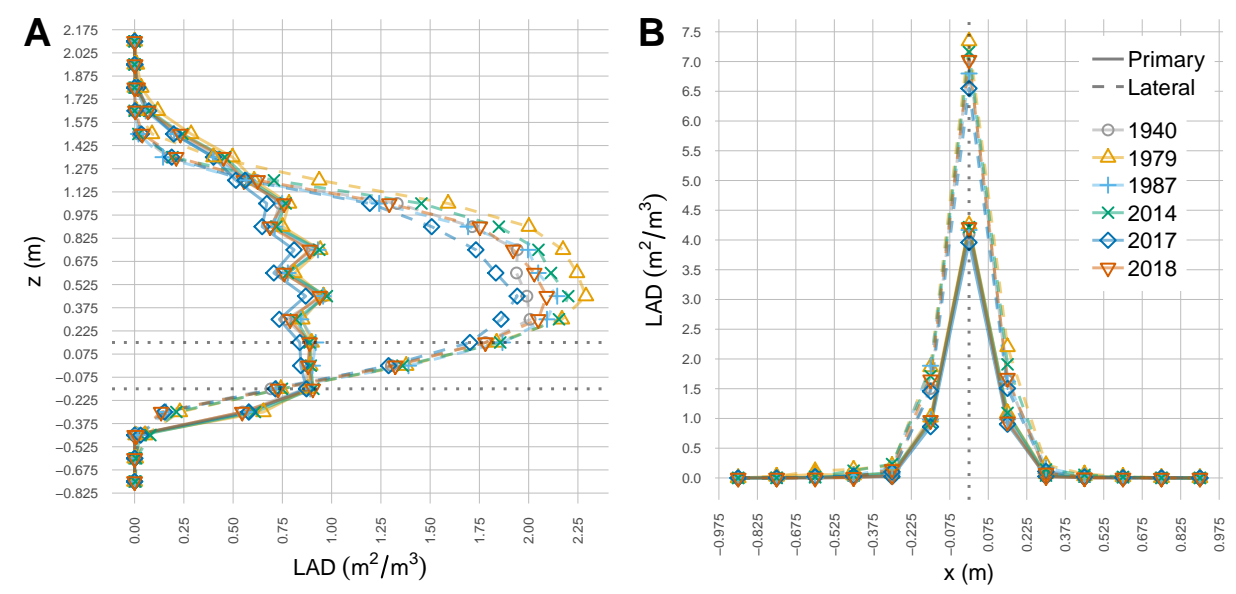

Figure 19. Leaf area density (LAD, $\mathrm{m}^{2} \mathrm{~m}^{-3}$ ) of primary and lateral leaves within the canopy section for: (A) horizontal ( $z$ : height relative to centre of bunch zone; dotted: bunch zone); and (B) vertical (left and right of cane, dotted: cane- $/ x$-axis) layers with a thickness $0.15 \mathrm{~m}$. 


\section{Conclusions}

We successfully developed a new functional-structural plant model Virtual Riesling based on digitised data of real plants grown in a vineyard and a comprehensive state-of-the-art data analysis. The model allows for the management technique "vertical shoot positioning" including bending of the shoots and subsequent reorientation of the canopy, the latter an intrinsic characteristic of the virtual canopy. We conducted an extensive simulation study based on Virtual Riesling using historical data of candidate years covering a 91-year timespan with some most distinct years. Simulation results reveal significant effects of the thermal time course over the year on primary and lateral bud breaks. High variabilities in these events affect canopy growth and leaf area distribution. All of them might have severe effects on crop management measures. The discussion of simulation output showed some discrepancies between reported data on leaf area characteristics such as the leaf area densities. We attributed this to the specific dataset used for model parameterisation. A more extensive dataset considering more plants and years with different temperature conditions as well as extended measurement periods should overcome this issue, when considered in future investigations. Despite the limitations, this report shows that a model such as Virtual Riesling could be used to assess the significance of changing temperatures for grapevine architecture and thereby considering management techniques such as vertical shoot positioning. Further developments of Virtual Riesling might support the knowledge gain for developing necessary adaptations in future vineyard management and, thus, facilitate future work on climate change research using functional-structural model approaches.

Author Contributions: Conceptualization, D.S., C.B., M.F. and K.K.; methodology, D.S., C.B., M.F. and K.K.; software, C.B.; validation, D.S., C.B., M.F. and K.K.; formal analysis, D.S.; investigation, D.S., M.F. and K.K.; resources, D.S., M.F. and K.K.; data curation, D.S. and C.B.; writing-original draft preparation, D.S., C.B., M.F. and K.K.; writing-review and editing, D.S., C.B., M.F. and K.K.; visualization, D.S. and C.B.; supervision, K.K.; project administration, D.S., M.F. and K.K.;

Funding: Funds for this study were provided by The Hessen State Ministry for Higher Education, Research and the Arts (HMWK).

Acknowledgments: The authors would like to thank the Geisenheim VineyardFACE team for facilitating the digitisation experiments and providing supplementary data.

Conflicts of Interest: The authors declare no conflict of interest.

\section{References}

1. van Leeuwen, C.; Darriet, P. The impact of climate change on viticulture and wine quality. J. Wine Econ. 2016, 11, 150-167. [CrossRef]

2. Francesca, S.; Simona, G.; Francesco Nicola, T.; Andrea, R.; Vittorio, R.; Federico, S.; Cynthia, R.; Maria Lodovica, G. Downy mildew (Plasmopara viticola) epidemics on grapevine under climate change. Glob. Chang. Biol. 2006, 12, 1299-1307. [CrossRef]

3. Bregaglio, S.; Donatelli, M.; Confalonieri, R. Fungal infections of rice, wheat, and grape in Europe in 2030-2050. Agron. Sustain. Dev. 2013, 33, 767-776. [CrossRef]

4. Keller, M.; Tarara, J.M. Warm spring temperatures induce persistent season-long changes in shoot development in grapevines. Ann. Bot. 2010, 106, 131-141. [CrossRef] [PubMed]

5. Lebon, E.; Pellegrino, A.; Tardieu, F.; Lecoeur, J. Shoot Development in Grapevine (Vitis vinifera) is Affected by the Modular Branching Pattern of the Stem and Intra- and Inter-shoot Trophic Competition. Ann. Bot. 2004, 93, 263-274, [CrossRef] [PubMed]

6. Luchaire, N.; Rienth, M.; Romieu, C.; Nehe, A.; Chatbanyong, R.; Houel, C.; Ageorges, A.; Gibon, Y.; Turc, O.; Muller, B.; et al. Microvine: A New Model to Study Grapevine Growth and Developmental Patterns and their Responses to Elevated Temperature. Am. J. Enol. Vitic. 2017, 68, 283-292, [CrossRef]

7. Pallas, B.; Loi, C.; Christophe, A.; Cournède, P.H.; Lecoeur, J. Comparison of three approaches to model grapevine organogenesis in conditions of fluctuating temperature, solar radiation and soil water content. Ann. Bot. 2010, 107, 729-745. [CrossRef] [PubMed]

8. Buttrose, M. Vegetative growth of grapevine varieties under controlled temperature and light intensity. Vitis $1969,8,280-285$. 
9. Parent, B.; Tardieu, F. Temperature responses of developmental processes have not been affected by breeding in different ecological areas for 17 crop species. New Phytol. 2012, 194, 760-774. [CrossRef] [PubMed]

10. Schultz, H.R.; Stoll, M. Some critical issues in environmental physiology of grapevines: Future challenges and current limitations. Aust. J. Grape Wine Res. 2010, 16, 4-24. [CrossRef]

11. Van Leeuwen, C.; Destrac-Irvine, A. Modified grape composition under climate change conditions requires adaptations in the vineyard. Oeno One 2017, 51, 147-154. [CrossRef]

12. Vos, J.; Evers, J.B.; Buck-Sorlin, G.H.; Andrieu, B.; Chelle, M.; De Visser, P.H. Functional-structural plant modelling: A new versatile tool in crop science. J. Exp. Bot. 2009, 61, 2101-2115. [CrossRef] [PubMed]

13. Stützel, H.; Kahlen, K. Editorial: Virtual Plants: Modeling Plant Architecture in Changing Environments. Front. Plant Sci. 2016, 7, 1734, [CrossRef] [PubMed]

14. Evers, J.B.; Letort, V.; Renton, M.; Kang, M. Computational botany: Advancing plant science through functional-structural plant modelling. Ann. Bot. 2018, 121, 767-772, [CrossRef]

15. Chen, T.W.; Stützel, H.; Kahlen, K. High light aggravates functional limitations of cucumber canopy photosynthesis under salinity. Ann. Bot. 2017, 121, 797-807, [CrossRef] [PubMed]

16. Chen, T.W.; Nguyen, T.; Kahlen, K.; Stützel, H. High temperature and vapor pressure deficit aggravate architectural effects but ameliorate non-architectural effects of salinity on dry mass production of tomato. Front. Plant Sci. 2015, 6, 887. [CrossRef] [PubMed]

17. Kahlen, K.; Chen, T.W. Predicting Plant Performance Under Simultaneously Changing Environmental Conditions-The Interplay Between Temperature, Light, and Internode Growth. Front. Plant Sci. 2015, 6, 1130, [CrossRef] [PubMed]

18. Cieslak, M.; Seleznyova, A.N.; Hanan, J. A functional-structural kiwifruit vine model integrating architecture, carbon dynamics and effects of the environment. Ann. Bot. 2010, 107, 747-764, [CrossRef] [PubMed]

19. Louarn, G.; Lebon, E.; Lecoeur, J. “Top-vine”, a topiary approach based architectural model to simulate vine canopy structure. In Proceedings of the XIV International GESCO Viticulture Congress, Geisenheim, Germany, 23-27 August 2005; Groupe d'Etude des Systemes de COnduite de la vigne (GESCO): Geisenheim, Germany, 2005; pp. 464-470.

20. Louarn, G.; Dauzat, J.; Lecoeur, J.; Lebon, E. Influence of trellis system and shoot positioning on light interception and distribution in two grapevine cultivars with different architectures: An original approach based on 3D canopy modelling. Aust. J. Grape Wine Res. 2008, 14, 143-152. [CrossRef]

21. Iandolino, A.; Pearcy, R.; Williams, L.E. Simulating three-dimensional grapevine canopies and modelling their light interception characteristics. Aust. J. Grape Wine Res. 2013, 19, 388-400. [CrossRef]

22. Zhu, J.; Gambetta, G.A.; Vivin, P.; Ollat, N.; Delrot, S.; Dai, Z.; Génard, M.; Vercambre, G. Growing grapes on a virtual plant. In Proceedings of the IEEE 2018 6th International Symposium on Plant Growth Modeling, Simulation, Visualization and Applications (PMA), Hefei, China, 4-8 November 2018 ; pp. 56-60.

23. Prieto, J.A.; Louarn, G.; Perez Pena, J.; Ojeda, H.; Simonneau, T.; Lebon, E. A leaf gas exchange model that accounts for intra-canopy variability by considering leaf nitrogen content and local acclimation to radiation in grapevine (Vitis vinifera L.). Plant Cell Environ. 2012, 35, 1313-1328. [CrossRef] [PubMed]

24. Garin, G.; Fournier, C.; Andrieu, B.; Houlès, V.; Robert, C.; Pradal, C. A modelling framework to simulate foliar fungal epidemics using functional-structural plant models. Ann. Bot. 2014, 114, 795-812. [CrossRef] [PubMed]

25. Zhu, J.; Dai, Z.; Vivin, P.; Gambetta, G.A.; Henke, M.; Peccoux, A.; Ollat, N.; Delrot, S. A 3-D functionalstructural grapevine model that couples the dynamics of water transport with leaf gas exchange. Ann. Bot. 2017, 121, 833-848. [CrossRef] [PubMed]

26. Zhu, J.; Génard, M.; Poni, S.; Gambetta, G.A.; Vivin, P.; Vercambre, G.; Trought, M.C.T.; Ollat, N.; Delrot, S.; Dai, Z. Modelling grape growth in relation to whole-plant carbon and water fluxes. J. Exp. Bot. 2018, 70, 2505-2521.10.1093/jxb/ery367. [CrossRef] [PubMed]

27. Albasha, R.; Fournier, C.; Pradal, C.; Chelle, M.; Prieto, J.A.; Louarn, G.; Simonneau, T.; Lebon, E. HydroShoot: A functional-structural plant model for simulating hydraulic structure, gas and energy exchange dynamics of complex plant canopies under water deficit - application to grapevine (Vitisvinifera L.). In Silico Plants 2019, [CrossRef]

28. Wohlfahrt, Y.; Smith, J.; Tittmann, S.; Honermeier, B.; Stoll, M. Primary productivity and physiological responses of Vitis vinifera L. cvs. under Free Air Carbon dioxide Enrichment (FACE). Eur. J. Agron. 2018, 101, 149-162, [CrossRef] 
29. Schulze-Sylvester, M.; Reineke, A. Elevated $\mathrm{CO}_{2}$ Levels Impact Fitness Traits of Vine Mealybug Planococcus ficus Signoret, but Not Its Parasitoid Leptomastix dactylopii Howard. Agronomy 2019, 9. [CrossRef]

30. Coombe, B. Growth stages of the grapevine: Adoption of a system for identifying grapevine growth stages. Aust. J. Grape Wine Res. 1995, 1, 104-110. [CrossRef]

31. Kahlen, K.; Stützel, H. Estimation of Geometric Attributes and Masses of Individual Cucumber Organs Using Three-dimensional Digitizing and Allometric Relationships. J. Am. Soc. Hortic. Sci. 2007, 132, 439-446. [CrossRef]

32. Schmidt, D.; Kahlen, K. Towards More Realistic Leaf Shapes in Functional-Structural Plant Models. Symmetry 2018, 10, 278. [CrossRef]

33. R Core Team. R: A Language and Environment for Statistical Computing; R Foundation for Statistical Computing: Vienna, Austria, 2019.

34. Goodrich, B.; Gabry, J.; Ali, I.; Brilleman, S. Rstanarm: Bayesian Applied regression Modeling via Stan., 2018. R Package Version 2.17.4. Available online: http:/ / mc-stan.org/ (accessed on 29 June 2019).

35. Bates, D.; Mächler, M.; Bolker, B.; Walker, S. Fitting Linear Mixed-Effects Models Using lme4. J. Stat. Softw. 2015, 67, 1-48, [CrossRef]

36. Schultz, H.R. An empirical model for the simulation of leaf appearance and leaf area development of primary shoots of several grapevine (Vitis vinifera L.) canopy-systems. Sci. Hortic. 1992, 52, 179-200. [CrossRef]

37. Nendel, C. Grapevine bud break prediction for cool winter climates. Int. J. Biometeorol. 2010, 54, $231-241$. [CrossRef]

38. Zalom, F.G.; Goodell, P.B. Degree Days: The Calculation and Use of Heat Units in Pest Management; University of California, Division of Agriculture and Natural Resources: Davis, CA, USA , 1983.

39. Beslic, Z.; Todic, S.; Tesic, D. Validation of non-destructive methodology of grapevine leaf area estimation on cv. Blaufränkisch (Vitis vinifera L.). S. Afr. J. Enol. Vitic. 2010, 31, 22-25. [CrossRef]

40. Döring, J.; Stöber, V.; Tittmann, S.; Kauer, R.; Stoll, M. Estimating leaf area and leaf area index in VSP trained grapevines under different management systems (Vitis vinifera cv. Riesling). In Proceedings of the 18th International Symposium GiESCO, Porto, Portugal, 7-11 July 2013.

41. Pratt, C. Vegetative anatomy of cultivated grapes-A review. Am. J. Enol. Vitic. 1974, 25, 131-150.

42. Adams, D.; Collyer, M.; Kaliontzopoulou, A. Geomorph: Software for Geometric Morphometric Analyses. R Package Version 3.1.0. Available online: https:/ / cran.r-project.org/package=geomorph (accessed on 29 June 2019).

43. Prusinkiewicz, P.; Lindenmayer, A. The Algorithmic Beauty of Plants; Springer Science \& Business Media: New York, NY, USA, 1990.

44. Kniemeyer, O. Design and Implementation of a Graph Grammar Based Language for Functional-Structural Plant Modelling. Ph.D. Thesis, Brandenburg University of Technology, Cottbus-Senftenberg, Germany, 2008.

45. Byrne, M. How many times should a stochastic model be run? An approach based on confidence intervals. In Proceedings of the 12th International Conference on Cognitive Modelling, University Park, PA, USA, 11 July 2013.; pp. 445-450.

46. Wickham, H. ggplot2: Elegant Graphics for Data Analysis; Springer-Verlag New York: New York, NY, USA, 2016.

47. Schultz, H. Grape canopy structure, light microclimate and photosynthesis. I. A two-dimensional model of the spatial distribution of surface area densities and leaf ages in two canopy systems. Vitis 1995, 34, 211-216.

48. Walther, G.R.; Post, E.; Convey, P.; Menzel, A.; Parmesan, C.; Beebee, T.J.; Fromentin, J.M.; Hoegh-Guldberg, O.; Bairlein, F. Ecological responses to recent climate change. Nature 2002, 416, 389. [CrossRef]

49. Diffenbaugh, N.S.; Singh, D.; Mankin, J.S. Unprecedented climate events: Historical changes, aspirational targets, and national commitments. Sci. Adv. 2018, 4. [CrossRef]

50. Siegfried, W.; Viret, O.; Huber, B.; Wohlhauser, R. Dosage of plant protection products adapted to leaf area index in viticulture. Crop Prot. 2007, 26, 73-82. [CrossRef]

51. Zahavi, T.; Reuveni, M.; Scheglov, D.; Lavee, S. Effect of grapevine training systems on development of powdery mildew. Eur. J. Plant Pathol. 2001, 107, 495-501. [CrossRef]

52. Austin, C.N.; Grove, G.G.; Meyers, J.M.; Wilcox, W.F. Powdery mildew severity as a function of canopy density: Associated impacts on sunlight penetration and spray coverage. Am. J. Enol. Vitic. 2011, 62, $23-31$. [CrossRef] 
53. Medrano, H.; Pou, A.; Tomás, M.; Martorell, S.; Gulias, J.; Flexas, J.; Escalona, J.M. Average daily light interception determines leaf water use efficiency among different canopy locations in grapevine. Agric. Water Manag. 2012, 114, 4-10, For a better use and distribution of water, [CrossRef]

54. Smart, R.; Dick, J.K.; Gravett, I.M.; Fisher, B. Canopy management to improve grape yield and wine quality-principles and practices. S. Afr. J. Enol. Vitic. 1990, 11, 3-17. [CrossRef]

55. Schultz, H.R. Extension of a Farquhar model for limitations of leaf photosynthesis induced by light environment, phenology and leaf age in grapevines (Vitis vinifera L. cvv. White Riesling and Zinfandel). Funct. Plant Biol. 2003, 30, 673-687. [CrossRef]

56. Louarn, G.; Guedon, Y.; Lecoeur, J.; Lebon, E. Quantitative Analysis of the Phenotypic Variability of Shoot Architecture in Two Grapevine (Vitis vinifera) Cultivars . Ann. Bot. 2007, 99, 425-437, [CrossRef]

57. Pallas, B.; Louarn, G.; Christophe, A.; Lebon, E.; Lecoeur, J. Influence of intra-shoot trophic competition on shoot development in two grapevine cultivars (Vitis vinifera). Physiol. Plant. 2008, 134, 49-63, [CrossRef]

58. Bindi, M.; Fibbi, L.; Miglietta, F. Free Air $\mathrm{CO}_{2}$ Enrichment (FACE) of grapevine (Vitis vinifera L.): II. Growth and quality of grape and wine in response to elevated $\mathrm{CO}_{2}$ concentrations. Eur. J. Agron. 2001, 14, 145-155. [CrossRef]

59. Escalona, J.; Flexas, J.; Medrano, H. Drought effects on water flow, photosynthesis and growth of potted grapevines. Vitis 2002, 41, 57-62.

60. Dry, P.; Loveys, B. Grapevine shoot growth and stomatal conductance are reduced when part of the root system is dried. Vitis 1999, 38, 151-156.

61. Kizildeniz, T.; Mekni, I.; Santesteban, H.; Pascual, I.; Morales, F.; Irigoyen, J.J. Effects of climate change including elevated $\mathrm{CO}_{2}$ concentration, temperature and water deficit on growth, water status, and yield quality of grapevine (Vitis vinifera L.) cultivars. Agric. Water Manag. 2015, 159, 155-164. [CrossRef]

62. Martínez-Lüscher, J.; Kizildeniz, T.; Vučetić, V.; Dai, Z.; Luedeling, E.; van Leeuwen, C.; Gomès, E.; Pascual, I.; Irigoyen, J.J.; Morales, F.; et al. Sensitivity of grapevine phenology to water availability, temperature and CO2 concentration. Front. Environ. Sci. 2016, 4, 48.

63. Pritchard, S.G.; Rogers, H.H.; Prior, S.A.; Peterson, C.M. Elevated $\mathrm{CO}_{2}$ and plant structure: A review. Glob. Chang. Biol. 1999, 5, 807-837. [CrossRef]

64. Bindi, M.; Raschi, A.; Lanini, M.; Miglietta, F.; Tognetti, R. Physiological and Yield Responses of Grapevine (Vitis vinifera L.) Exposed to Elevated $\mathrm{CO}_{2}$ Concentrations in a Free Air $\mathrm{CO}_{2}$ Enrichment (FACE). J. Crop Improv. 2005, 13, 345-359, [CrossRef] 